\title{
Stimuli-responsive polymeric nanomaterials for rheumatoid arthritis therapy
}

\author{
Yingsi Xie ${ }^{1,3}$, Ruslan G. Tuguntaev ${ }^{1}$, Cong Mao ${ }^{1}$, Haoting Chen ${ }^{1}$, \\ Ying Tao $^{1}$, Shixiang Wang ${ }^{4 凶}$, Bin Yang ${ }^{2}$, Weisheng Guo ${ }^{1 凶}$ \\ 1 Translational Medicine Center, Key Laboratory of Molecular Target \& Clinical Pharmacology, School of \\ Pharmaceutical Sciences \& The Second Affiliated Hospital, Guangzhou Medical University, Guangzhou 510260, \\ China \\ 2 The Sixth Affiliated Hospital, Department of Biomedical Engineering, School of Basic Medical Sciences, Guangzhou \\ Medical University, Guangzhou 511436, China \\ ${ }^{3}$ Université Paris 13, 99 avenue Jean Baptiste Clément, 93430 Villetaneuse, France \\ ${ }^{4}$ Department of Cardiovascular Medicine, The Third Affiliated Hospital, Guangzhou Medical University, \\ Guangzhou 510260, China
}

Received: 1 June 2020 / Accepted: 15 July 2020 / Published online: 6 October 2020

\begin{abstract}
Rheumatoid arthritis (RA) is a long-term inflammatory disease derived from an autoimmune disorder of the synovial membrane. Current therapeutic strategies for RA mainly aim to hamper the macrophages' proliferation and reduce the production of pro-inflammatory cytokines. Therefore, the accumulation of therapeutic agents targeted at the inflammatory site should be a crucial therapeutic strategy. Nowadays, the nanocarrier system incorporated with stimuli-responsive property is being intensively studied, showing the potentially tremendous value of specific therapy. Stimuli-responsive (i.e., $\mathrm{pH}$, temperature, light, redox, and enzyme) polymeric nanomaterials, as an important component of nanoparticulate carriers, have been intensively developed for various diseases treatment. A survey of the literature suggests that the use of targeted nanocarriers to deliver therapeutic agents (nanotherapeutics) in the treatment of inflammatory arthritis remains largely unexplored. The lack of suitable stimuli-sensitive polymeric nanomaterials is one of the limitations. Herein, we provide an overview of drug delivery systems prepared from commonly used stimuli-sensitive polymeric nanomaterials and some inorganic agents that have potential in the treatment of RA. The current situation and challenges are also discussed to stimulate a novel thinking about the development of nanomedicine.
\end{abstract}

Keywords Rheumatoid arthritis, Nanotechnology, Stimuli-responsive polymers, Drug delivery systems

\section{INTRODUCTION}

Rheumatoid arthritis (RA) is a long-term inflammatory disease derived from an autoimmune disorder of the synovial membrane (McInnes and O'Dell 2010; McInnes

Yingsi Xie and Ruslan G. Tuguntaev contributed equally to this work.

$\bowtie$ Correspondence: tjuguoweisheng@126.com (S. Wang), bin.yang@gzhmu.edu.cn (B. Yang), 630311325@qq.com (W. Guo) and Schett 2017; Smolen et al. 2012). It causes clinically acute pain, swelling, progressive cartilage damage, and bone erosion, which severely affects life quality, even increases the mortality rate (Oliveira et al. 2018). While the cause of rheumatoid arthritis is not very clear, the underlying mechanism of pathogenesis involves the immune system attacking the joints. The major evidence from genetics, tissue analyses, and clinical studies points to an immune-mediated etiology associated with stromal tissue dysregulation that together propagate 
chronic inflammation and articular destruction. A preRA phase can last months to years in patients. It may alter metabolism by the presence of circulating autoantibodies, which increases concentration and range of inflammatory cytokines and chemokines (Firestein and McInnes 2017). Studies over the last several decades have identified that macrophages play a crucial role in the occurrence and perpetuation of RA. Macrophages are activated by a combination of genetic and environmental factors, of these, the strongest associations have been seen with female sex, a family history of RA, the genetic factor, the shared epitope, and exposure to tobacco smoke (Deane et al. 2017). When macrophages are activated, a variety of pro-inflammatory cytokines (tumor necrosis factor-alpha (TNF- $\alpha$ ), interleukin-1 beta (IL-1 $\beta$ ), IL-6, etc.) are excessively secreted in synovial fluid and evoke inflammation and joint destruction (Aletaha and Smolen 2018; Jain et al. 2015; Pham 2011). Animal models provide further evidence of the importance of these cytokines in RA development mechanism. Mice expressing a dysregulated and modified human TNF transgene developed spontaneous arthritis. A monoclonal antibody against human TNF- $\alpha$ as a therapeutic approach can completely inhibit the development of this disease (Keffer et al. 1991). Hence, current therapeutic strategies for RA are mainly aiming to reduce the production of pro-inflammatory cytokines (Lima and Reis 2015).

RA therapy is complex and includes various classes of medications with different mechanisms of action. Conventional drugs for RA treatment generally fall into four groups: non-steroidal anti-inflammatory drugs (NSAIDs) (Sostres et al. 2010), glucocorticoids (GCs) (Smolen et al. 2018; Vandewalle et al. 2018), non-biological disease-modifying anti-rheumatic drugs (DMARDs), and biological DMARDs (Quan et al. 2008). However, RA remains a non-curable disease, its treatment aims to relieve pain and to impede the inflammatory and destructive processes, and the final goal is to achieve remission or at least low disease activity. Such a strategy requires frequent and long-term treatments that can cause undesirable systemic side effects due to the lack of tissue specificity and inability to selectively target the inflammatory areas. Short biological half-life and low bioavailability of conventional drugs also contribute to a low therapeutic index (Guo et al. 2018). These limitations have driven the development and application of nanomaterial-based devices in the treatment of RA.

Nanomedicines (NMs) offer multiple benefits over conventional drugs in RA treatment. Above all, their site-specific and target-oriented drug delivery is demonstrated thanks to nanoparticles' detection and responses to stimuli from the micro- or macroenvironment. Depending on the nature of the process, the responsible stimuli can be divided into three groups: physical (e.g., temperature, light, magnetic/electric field), chemical (e.g., pH, redox), and biological (e.g., enzymes, endogenous receptors) (Indermun et al. 2018; Lopes et al. 2013) (Fig. 1). Besides, long circulation time and high bioavailability are their important advantages, due to their appropriate size and easily modified surface (Patra et al. 2018). Recently, NMs have been demonstrated as an effective approach for specific drug delivery in the inflammatory tissues. Encapsulation of therapeutic drugs into a nanosized drug delivery system allowing accurate drug delivery can increase drug absorption and biodistribution in affected sites resulting in enhanced therapeutic efficacy. Furthermore, surface functionalization or surface coating is considered as a crucial parameter for improving the targeting efficiency and can increase cellular uptake. For instance, folic acid, a stable and non-immunogenic ligand that has a high affinity to cell surface folate receptor (FR), was employed as a targeting moiety of the dendrimer to attain specific targeting since FR is overexpressed on activated (but not quiescent) macrophage (Nogueira et al. 2016). Liu et al. reported another example of specific delivery of anti-rheumatic drugs without using targeting ligands (Liu et al. 2019). The authors found overexpression of SPARC (secreted protein acidic and rich in cysteine) in the synovial fluid and synovium during RA. Motivated by the high affinity of SPARC for albumin, they developed methotrexate (MTX)-loaded human serum albumin (HSA) NMs (MTX@HSA NMs) for biomimetic drug delivery (Fig. 2). Besides, since arthritic joints consume higher amounts of albumin than healthy tissues, increased demand for albumin by arthritic joints can contribute to specific drug delivery. The fabricated nanotherapeutics were intravenously injected into mice with collagen-induced arthritis (CIA). The fluorescence/magnetic resonance dual-modal imaging analysis displayed a higher accumulation and prolonged retention time of MTX@HSA NMs in arthritic joints as compared to free HSA and MTX molecules. In vivo evaluations evidenced that unlike free MTX, the MTX@HSA NMs had a superior therapeutic index and fewer side effects. Moreover, the results also demonstrated higher RA treatment efficacy of nanoformulation even at a half dose of administrated MTX for free MTX.

Site-specific delivery of the drugs can also be achieved by using "smart" NMs fabricated of stimuliresponsive materials that can recognize microenvironment and response in a dynamic way. Application of stimuli is responsible for alteration/disruption of the structure of specifically designed nanocarriers, resulting 


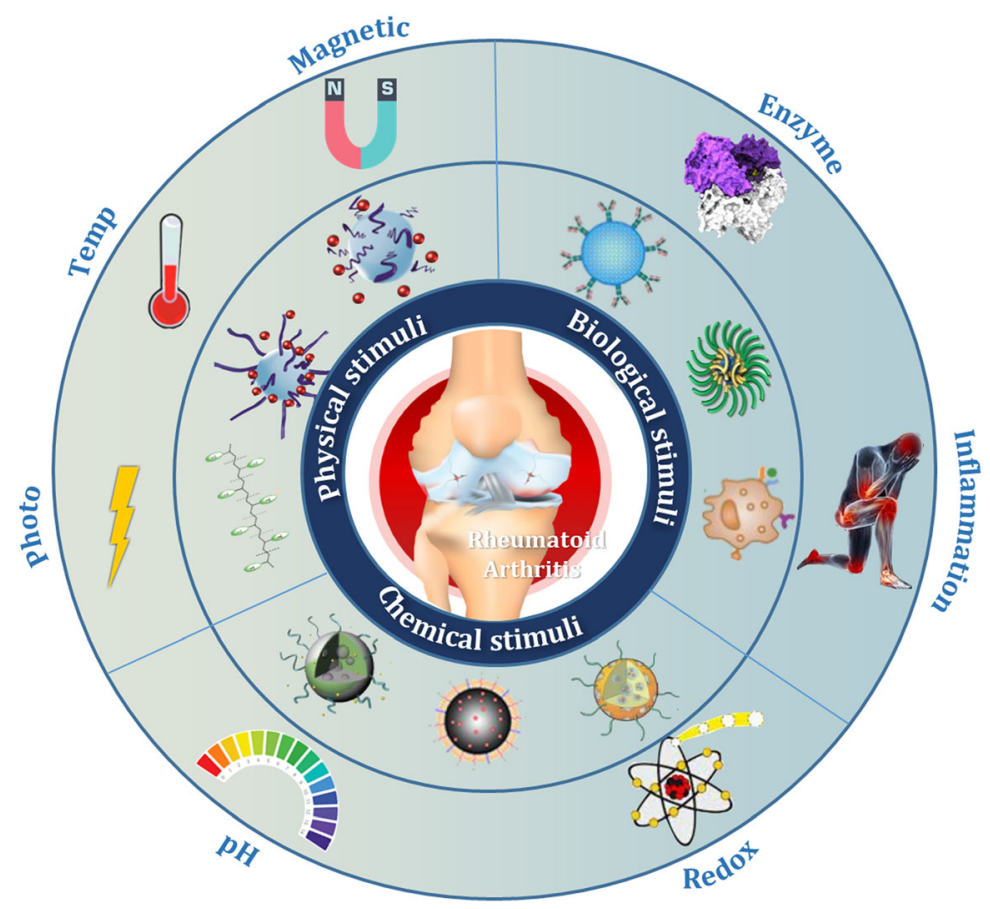

Fig. 1 Schematic illustration of stimuli-responsive polymers for rheumatoid arthritis therapy

in drug release at the targeted site (Stuart et al. 2010). The advances in the past 10 years on the use of stimuliresponsive polymeric nanoparticles for the treatment of RA were summarized in Table 1.

These triggered systems can be sensitive to various endogenous stimuli, such as lowered interstitial $\mathrm{pH}$, an enhanced concentration of certain enzymes, or a high level of glutathione. At the cellular level, $\mathrm{pH}$-sensitive nanocarriers can either induce the release of the encapsulated drug into late endosomes or lysosomes, or stimulate the escape of nanodevices from the lysosomes to the cell cytoplasm (Karimi et al. 2016a). At the tissue level, stimuli-responsive NMs can take advantage of microenvironmental features associated with pathological conditions including neoplastic diseases, inflammation, ischemia, or infections. External stimuli can also be applied. For instance, the specific delivery of therapeutic agents to the desired tissues can be magnetically guided by inorganic agents, such as ultrasmall iron oxide-based nanoparticles. Sustained drug release can also be achieved by light-, thermo-, or ultrasoundsensitive nanocarriers (Mura et al. 2013; Raza et al. 2019).

The fabrication of stimuli-responsive nanocarriers requires the use of biocompatible materials, which are able to undergo supramolecular conformational changes, specific protonation, hydrolytic cleavage, etc. The most appropriate and widely explored category of materials that possess a potentially tremendous value of specific therapy is polymers of both natural and synthetic origin. The versatility of polymer sources and the ability of their combinatorial synthesis make it possible to control polymer sensitivity to a certain stimulus within a narrow range (James et al. 2014). Moreover, ease of polymers modification can lead to increased biocompatibility and reduced toxicity. Many synthetic stimuli-responsive polymers including thermo-responsive pluronic F127 (PF127), which is a non-ionic triblock copolymer of poly(ethylene oxide)-bpoly(propylene oxide)-b-poly(ethylene oxide) (PEOPPO-PEO), or poly( $N$-isopoprylacrilamide) (pNIPAAm) had been approved by U.S. Food and Drug Administration (FDA) for biomedical applications, especially for drug delivery and tissue engineering (Chatterjee and Hui 2019). In this review, we focused on the latest progress of stimuli-responsive polymeric NMs for RA therapy. Some existing studies and thinking on NMs are also discussed.

\section{STIMULI-RESPONSIVE POLYMERIC NANOMATERIALS}

Polymeric materials are one of the most commonly used building blocks for the preparation of drug delivery systems. They are becoming increasingly important in the biomedical field since they offer several advantages, 


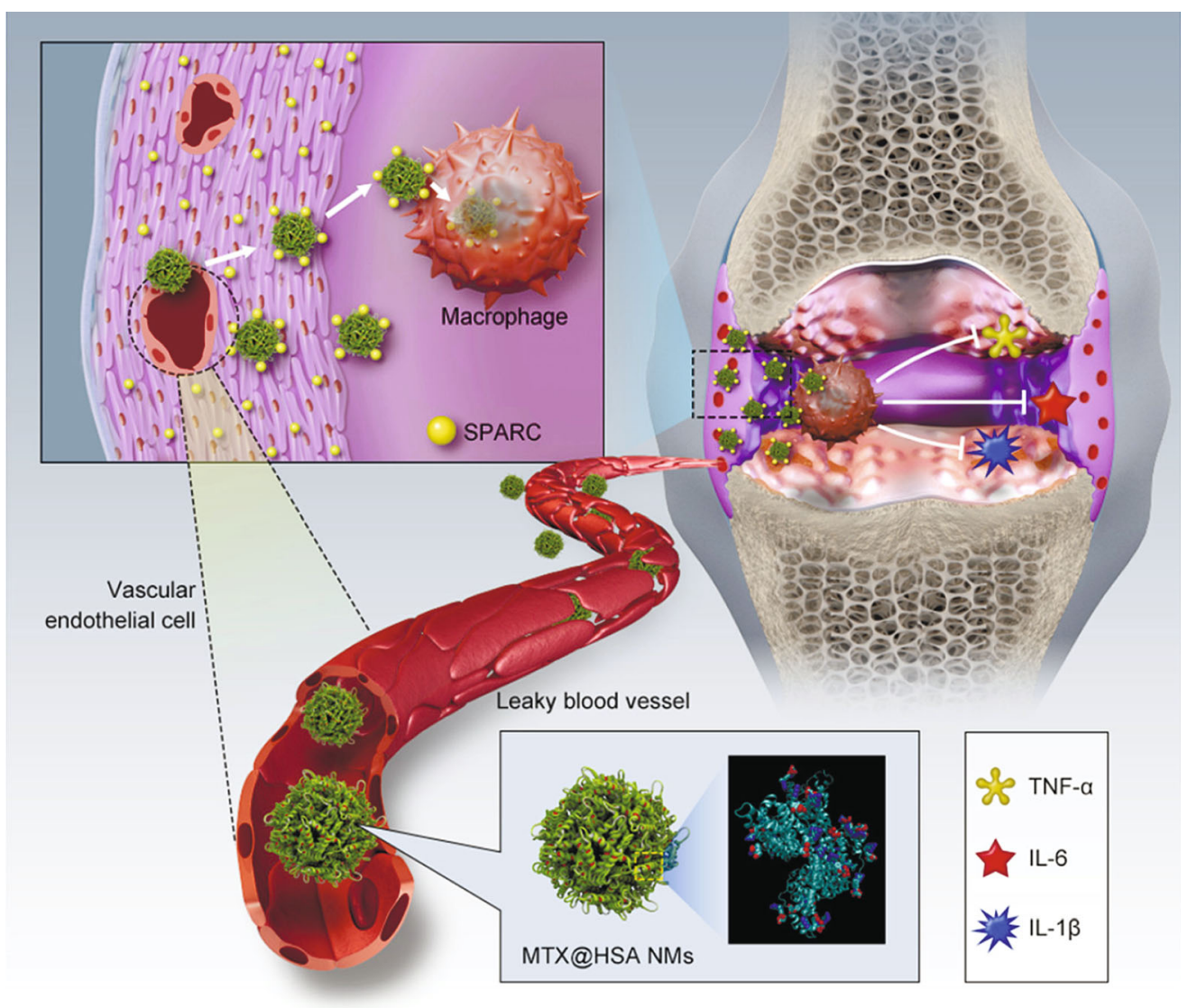

Fig. 2 Schematic representation of delivery of MTX@HSA NMs in RA joints. High accumulation of MTX@HSA NMs in the synovium is provided by leaky vessels, enhanced demand for albumin of arthritic joints, and high affinity between HAS and SPARC. After that, activated macrophages take up the MTX@HSA NMs that subsequently inhibit the secretion of pro-inflammatory cytokines, resulting in attenuation of RA (Liu et al. 2019)

as compared to other materials, such as high synthetic flexibility, ability to be precisely tailored according to their specific application, biological functionality, biodegradation, biocompatibility, and suitable mechanical properties (Song et al. 2018). Stimuli-sensitive polymers undergo an abrupt change in their physical properties in response to various stimuli from the microenvironment or macroenvironment (Siafaka et al. 2016; Yang et al. 2014). The main polymer transitions can be attributed to changes in shape, physical state, solubility, hydrophilic/lipophilic balances, solvent interactions, and conductivity. The driving forces behind these alterations include simple chemical reactions such as reduction-oxidation, acid-base reaction, or hydrolysis of moieties linked to the polymer chain. Some of the changes are reversible because of the polymers' ability to return to the original state after the trigger is removed. In some cases, external stimuli cause irreversible bond breakage leading to degradation and dramatic conformational change in the polymeric structure (James et al. 2014). Polymeric nanoparticles
(PNPs) account for a great proportion in stimuliresponsive nanocarriers including nanocapsules, nanospheres, liposomes, polymeric micelles, dendrimers, etc. (Fig. 3). The major benefits of sensitive drug delivery systems include accurate drug delivery, controlled payload release, increased duration time of therapeutic agents in the body, improved stability, and reduced dosing frequency. These benefits can ultimately improve the therapeutic index and reduce systemic side effects of conventionally used drugs. Novel strategies for RA treatment are usually modeled after oncology and apply the same polymeric materials with or without structural changes that are adopted for the specific features of RA. Herein, we introduce strategies of RA treatment that take advantage of applying stimuli-sensitive PNPs.

\section{pH-responsive PNPs}

$\mathrm{pH}$ shift has been exploited to trigger the release of incorporated therapeutics when environmental alterations are associated with pathological conditions, such 
Table 1 The published articles on the use of stimuli-responsive polymeric nanoparticles for the treatment of RA

\begin{tabular}{|c|c|c|c|c|}
\hline $\begin{array}{l}\text { Type of } \\
\text { stimuli }\end{array}$ & Stimulus & Description of the system & Drug & References \\
\hline \multirow[t]{6}{*}{ Chemical } & \multirow[t]{6}{*}{$\mathrm{pH}$} & $\begin{array}{l}\text { Mineralized nanoparticles composed of PEGylated hyaluronic acid (P-HA) as the } \\
\text { hydrophilic shell, } 5 \beta \text {-cholanic acid as the hydrophobic core, and CaP as the } \\
\text { pH-responsive mineral }\end{array}$ & MTX & $\begin{array}{c}\text { Alam et al. } \\
\text { (2017) }\end{array}$ \\
\hline & & $\begin{array}{l}\text { Hyaluronic acid (HA) coated acid-sensitive polymeric nanoparticles (HAPNPs) } \\
\text { composed of egg phosphatidylcholine, polyethylenimine, and PCADK }\end{array}$ & Dex & $\begin{array}{l}\text { Yu et al. } \\
\quad \text { (2019) }\end{array}$ \\
\hline & & $\begin{array}{l}\text { Stearic acid-octa-arginine and folic acid decorated PLGA -PK3-based lipid } \\
\text { polymeric hybrid nanoparticles (Sta-R8-FA-PPLPNs/MTX) composed of PK3, } \\
\text { Folate-PEG-PLGA, egg PC, and Sta-R8 }\end{array}$ & MTX & $\begin{array}{l}\text { Zhao et al. } \\
\text { (2018) }\end{array}$ \\
\hline & & $\begin{array}{l}\text { Poly( } \beta \text {-amino ester)-graft-poly(ethylene glycol) (PAE-g-PEG) self-assembled into } \\
\text { spherical micelles and MTX loaded into the hydrophobic core of micelles }\end{array}$ & MTX & $\begin{array}{l}\text { Moon et al. } \\
\quad(2020)\end{array}$ \\
\hline & & $\begin{array}{l}\text { Multifunctional FA receptor-targeting and pH-responsive } \\
\text { nanocarriers composed of lipids, PEG-PLGA forming a hydrophilic shell, folic } \\
\text { acid (FA) around the hydrophilic shell as a targeting ligand, and } \\
\text { poly(cyclohexane-1,4-diylacetone dimethylene ketal) (PCADK) and PLGA as a } \\
\text { hydrophobic core. PCADK also as a pH-responsive material }\end{array}$ & MTX & $\begin{array}{l}\text { Zhao et al. } \\
\text { (2017) }\end{array}$ \\
\hline & & $\begin{array}{l}\text { Modular pH-sensitive acetone-based ketal-linked prodrugs of dexamethasone } \\
\text { (AKP-dexs) nanoparticles }\end{array}$ & Dex & $\begin{array}{l}\text { Xu et al. } \\
\quad(2020)\end{array}$ \\
\hline Physical & NIR & $\begin{array}{l}\text { RGD-attached gold }(\mathrm{Au}) \text { half-shell nanoparticles containing methotrexate (MTX), } \\
\text { RGD peptide as targeting moiety for inflammation }\end{array}$ & MTX & $\begin{array}{r}\text { Lee } \text { et al. } \\
\text { (2013) }\end{array}$ \\
\hline Biological & Redox (ROS) & $\begin{array}{l}\text { Folate conjugated to PEC } 100 \text { monostearate as film-forming material, and } \\
\text { methotrexate (MTX) and catalase (CAT) co-encapsulated liposomes (FOL- } \\
\text { MTX\&CAT-L) }\end{array}$ & MTX & $\begin{array}{l}\text { Chen et al. } \\
\text { (2019b) }\end{array}$ \\
\hline \multirow[t]{2}{*}{ Combined } & $\begin{array}{l}\text { Temperature and } \\
\text { pH }\end{array}$ & $\begin{array}{l}\text { Methotrexate(MTX) and gold }(\mathrm{Au}) \text { nanoparticles incorporated in the pegylated- } \\
\text { poly(DL-lactic-co-glycolic acid) nanospheres }\end{array}$ & MTX & $\begin{array}{l}\text { Lima and } \\
\text { Reis } \\
(2015)\end{array}$ \\
\hline & $\begin{array}{l}\text { NIR and external } \\
\text { magnetic field }\end{array}$ & $\begin{array}{l}\text { MTX-loaded poly(lactic-co-glycolic acid) (PLGA) gold }(\mathrm{Au}) / \text { iron }(\mathrm{Fe}) / \text { gold }(\mathrm{Au}) \\
\text { half-shell nanoparticles conjugated with arginine-glycine-aspartic acid (RGD) }\end{array}$ & MTX & $\begin{array}{c}\text { Kim et al. } \\
\quad(2015)\end{array}$ \\
\hline
\end{tabular}

as inflammation (Karimi et al. 2016a). It is well known, that the normal knee-joints have a physiological $\mathrm{pH}$ of 7.3, while the $\mathrm{pH}$ value of rheumatoid inflammatory tissues is intrinsically acidic (pH 6.6) (Goldie and Nachemson 1969). The drop in $\mathrm{pH}$ is related to infiltration and activation of inflammatory cells in the synovial tissues, resulting in enhanced energy and oxygen demand. Accelerated glucose consumption via glycolysis results in increased lactic acid production, which leads to the local acidosis (Borregaard and Herlin 1982; Menkin 1956; Rajamäki et al. 2013; Roiniotis et al. 2009). Importantly, in RA patients, the low synovial $\mathrm{pH}$ correlates with high disease activity and joint destruction (Farr et al. 1985; Geborek et al. 1989). In this regard, the strategy of using $\mathrm{pH}$-sensitive PNPs bearing therapeutic agents (NSAIDs, GCs) has great potential in RA treatment. The nanosystems with an appropriate size can effectively penetrate inflamed joints by taking advantage of enhanced angiogenesis during RA, which leads to discontinuity of inflammatory endothelial cells and increased vascular permeability (Peper et al. 2017; Wang et al. 2020). After sensitive nanocarriers have delivered anti-RA drugs to the affected area, low $\mathrm{pH}$ conditions trigger the drug release precisely into its site of action. Applying this method makes it possible to enhance the efficacy of RA treatment by improving therapeutic selectivity and reducing systemic side effects.

The rational design of $\mathrm{pH}$-sensitive nanoparticles is based on two main strategies: the use of polymeric carriers with acid-sensitive bonds, which under low $\mathrm{pH}$ conditions are cleaved, resulting in the release of molecules anchored at the polymer backbone; and the use of polymers (polybases or polyacids) with ionizable groups that undergo a pH-dependent conformational or solubility changes (Murthy et al. 2003; Yang et al. 2014). Some of the $\mathrm{pH}$-sensitive polymers employed in the field of nanomedicine are summarized in Table 2.

Researchers have designed new approaches to attain targeted release by nanocarrier surface functionality and coating. It was demonstrated that the strategy of simultaneous use of $\mathrm{pH}$ responsiveness and active targeting could markedly improve therapeutic specificity in RA treatment. Yu et al. investigated a modification of 


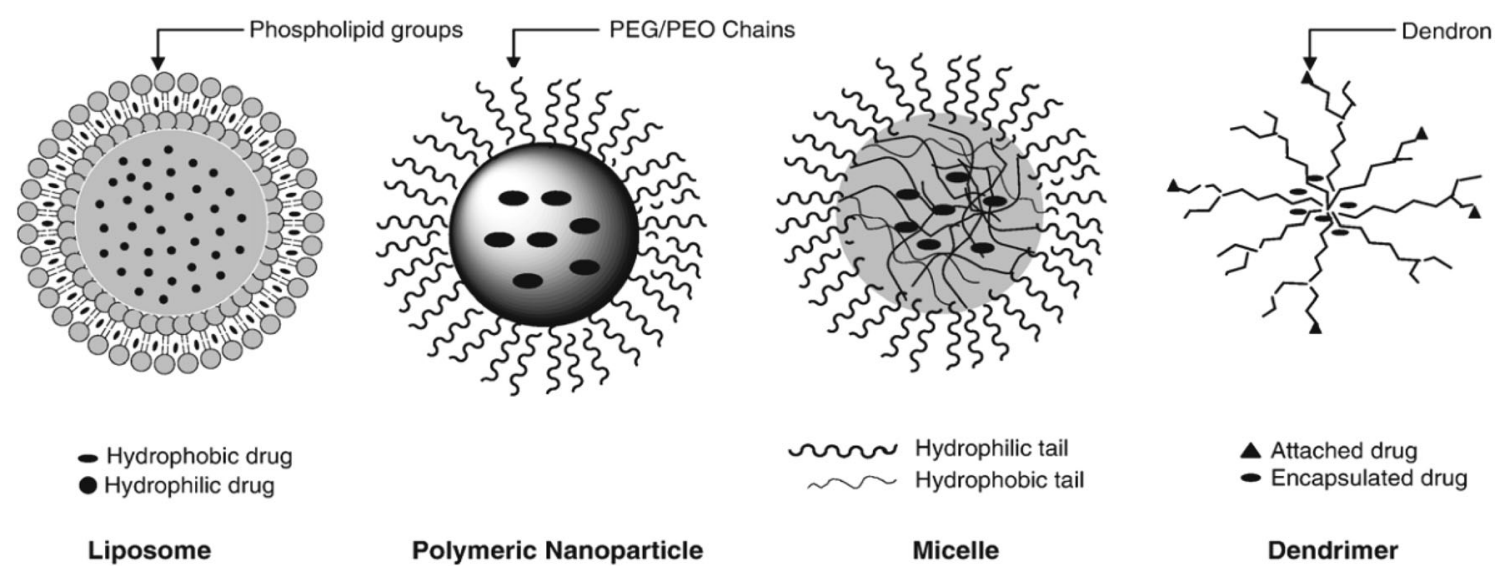

Fig. 3 Schematic representation of different types of stimuli-responsive nanocarriers (Ganta et al. 2008)

hyaluronic acid (HA) coated acid-sensitive PNPs (HAPNPs) loaded with dexamethasone (Dex) for the treatment of RA (Yu et al. 2019). The acid-sensitive polymeric material is composed of egg phosphatidylcholine, polyethylenimine, poly(cyclohexane-1,4-diyl acetone dimethylene ketal) (PCADK), a member of the polyketal family, which has excellent acid sensitivity. HA was selected as a targeting moiety due to its ability to bind CD44, an adhesion receptor, which is overexpressed on the surface of activated macrophages in RA patients. It was verified, that the fabricated nanosystem with an average diameter of $150.5 \mathrm{~nm}$, possessed a marked pH-dependent drug release behavior. The presence of HA on the surface of nanoparticles enabled high targeting ability of HAPNPs towards activated macrophages, which was confirmed by cellular uptake studies using confocal laser scanning microscopy. Finally, in vivo experiments in adjuvant-induced arthritis (AIA) rat models showed that the inflammatory cell infiltration, bone damage, and cartilage damage were reduced in the ankle joints under the treatment by HAPNPs/Dex. An increased curative effect was attained most likely due to the $\mathrm{pH}$ sensitivity of HAPNPs and their targeting ability to the activated macrophages (Fig. 4).

Despite polymeric materials, inorganic components can also be applied to provide pH-responsible behavior of the fabricated nanosystem. Such a system was developed by Alam et al. (Alam et al. 2017). They reported mineralized nanoparticles (MP-HANPs) composed of PEGylated hyaluronic acid (P-HA) as the hydrophilic shell, $5 \beta$-cholanic acid as the hydrophobic core, with a calciumphosphate (CaP) as the pH-responsive mineral (Fig. 5A). The presence of CaP as the diffusion barrier enabled $\mathrm{pH}$-responsive release kinetics of incorporated MTX across neutral to acidic conditions. HANPs were internalized in macrophages via receptor-mediated endocytosis, and later MP-HANPs loaded with doxorubicin demonstrated a $\mathrm{pH}$-dependent payload release into the cytosol (Fig. 5B). Further animal studies showed a substantially high paw-to-liver ratio of fluorescent intensity after injection of MPHANPs loaded with Cy5.5, suggesting improved biodistribution of prepared drug delivery system. Treatment with MTX-loaded MP-HANPs alleviated progression CIA in mice with high safety even when using high doses of MTX.

In some cases, pH-responsible drug release can be achieved by the fabrication of nanocarrier's core through the simple physical mixing of acid-sensitive and non-sensitive polymers. For instance, Zhao et al. designed dual-functional lipid polymeric hybrid pH-responsive nanoparticles against RA (Zhao et al. 2018). The polymeric core of the system was composed of pH-responsible polyketal (PK3) and conventional PEG-PLGA building blocks. Moreover, the nanoparticles were decorated with folate targeting ligand and hydrophobic derivatives of octa-arginine with stearic acids (Sta-R8) for penetrating macrophages (Fig. 6). MTX was used as an anti-RA drug. The obtained data showed that in vitro release of MTX from formulated particles (size 100-150 nm) was faster under acidic conditions ( $\mathrm{pH}$ 5.0) as compared to physiological $\mathrm{pH}$ of 7.4 , suggesting apparent $\mathrm{pH}$-responsive characteristic of the nanocarrier. The cellular studies revealed that the presence of folate and Sta-R8 on the surface of nanoparticles improved their uptake efficiency and cytotoxicity. Further in vivo therapeutic effects studies indicated that fabricated nanosystem has good therapeutic effects for AIA on rats due to inhibiting the secretion of pro-inflammatory cytokines.

The traditional design of stimuli-responsive NMs is based on the incorporation of drug molecules into the nanocarrier, which is prepared from $\mathrm{pH}$-sensitive 
Table 2 Examples of pH-sensitive polymeric materials which can be applied for RA therapy

\begin{tabular}{|c|c|c|c|c|}
\hline Polymeric material & $\begin{array}{l}\text { Size of } \\
\text { nanoparticles } \\
(\mathrm{nm})\end{array}$ & Stimulus & $\begin{array}{l}\text { Response } \\
\text { pH value }\end{array}$ & References \\
\hline Poly(2-tetrahydropyranyl methacrylate) & 314 & pH (acetal bone) & 5.1 & $\begin{array}{l}\text { Jung et al. } \\
\text { (2007) }\end{array}$ \\
\hline Poly(ethylene oxide)-poly( $\beta$-amino ester $)$ & $150-200$ & $\begin{array}{l}\mathrm{pH} \text { (dissolution } \\
\text { mechanism) }\end{array}$ & $<6.5$ & $\begin{array}{l}\text { Shenoy et al. } \\
\text { (2005) }\end{array}$ \\
\hline $\begin{array}{l}\text { Poly(ethylenimine)-poly(methacryloyl sulfadimethoxine) (PSD)- } \\
\text { block-PEG }\end{array}$ & 300 & $\begin{array}{l}\mathrm{pH} \text { (sulfonamide } \\
\text { group) }\end{array}$ & 6.6 & $\begin{array}{l}\text { Sethuraman } \\
\text { et al. }(2006)\end{array}$ \\
\hline Poly(ethylene glycol)-poly(L-histidine)-poly(L-lactide) & 803 & $\begin{array}{l}\text { pH (imidazole } \\
\text { group) }\end{array}$ & 5.0 & $\begin{array}{l}\text { Liu et al. } \\
\text { (2011) }\end{array}$ \\
\hline Chitosan-histidine-arginine & 105 & $\begin{array}{l}\text { pH (imidazole } \\
\text { group) }\end{array}$ & $6-5$ & $\begin{array}{l}\text { Gaspar et al. } \\
\text { (2013) }\end{array}$ \\
\hline $\begin{array}{l}\text { (5-Methyl-2-(2,4,6-trimethoxyphenyl)-[1,3]-5-dioxanylmethyl } \\
\text { methacrylate) and (1,4-0-methacryloylhydroquinone) }\end{array}$ & $20-100$ & $\mathrm{pH}$ (acetal bone) & 5 & $\begin{array}{l}\text { Zubris et al. } \\
\text { (2013) }\end{array}$ \\
\hline PEG-aldehyde functionalized dextran-DOX & 100 & $\begin{array}{l}\mathrm{pH} \text { (imine } \\
\text { bonds) }\end{array}$ & 5.5 & $\begin{array}{l}\text { Sagnella et al. } \\
\text { (2014) }\end{array}$ \\
\hline Poly(oligoethylene glycol) methyl ether acrylate & $10-20$ & $\begin{array}{l}\mathrm{pH} \text { (imine } \\
\text { bonds) }\end{array}$ & 5.5 & $\begin{array}{l}\text { Liu et al. } \\
\text { (2012) }\end{array}$ \\
\hline $\begin{array}{l}\text { Poly(oligoethylene methoxy acrylate) modified with NO donor } \\
\text { molecules }\end{array}$ & 32 & $\mathrm{pH}$ & $<7.0$ & $\begin{array}{l}\text { Duong et al. } \\
\quad(2014)\end{array}$ \\
\hline Poly(lactic-co-glycolic acid) and eudragit S-100 & 250 & $\begin{array}{l}\mathrm{pH}(\text { dissolution } \\
\text { mechanism) }\end{array}$ & $>7.57$ & $\begin{array}{l}\text { Zhang et al. } \\
\text { (2011) }\end{array}$ \\
\hline
\end{tabular}

building blocks. However, under acidic conditions, drug delivery systems tend to demonstrate burst drug release instead of extended-release. Moreover, the delivery systems also suffer from the lack of adequate drug loading capacity. The reasons of these phenomena might be attributed to the poor compatibility between encapsulated cargo and nanocarriers (van der Meel et al. 2019). In this regard, it becomes pivotal to initiate the finding of innovative strategies to optimize the design of stimuli-responsive NMs. Xu et al. proposed an interesting solution to this issue (Xu et al. 2020). They developed a Dex prodrug, which was linked via pH-sensitive acetone-based ketals with differently structured pro-moieties. The prodrugs then were loaded into FDA-approved 1,2-distearoyl-sn-glycero-3-phosphoethanol-amine-poly(ethylene glycol) (DSPEmPEG2000) to formulate NMs for RA treatment (Fig. 7). Better compatibility between Dex and DSPE-mPEG2000, and thus, good stability and high encapsulation efficiency, were achieved by modifying the drug with longcarbon-chain alcohols as pro-moieties: stearyl alcohol and 2-nonadecanol. The synthesized Dex prodrugs were indicated as stearyl alcohol-ketal-Dex (SKD) and 2-nonadecanol-ketal-Dex (2'NKD). SKD-loaded DSPEmPEG2000 nanoparticles and 2'NKD-loaded DSPEmPEG2000 nanoparticles were used for further evaluations. The nanoparticles with the mean particle sizes of
10-200 nm demonstrated an effective ability to target the inflamed synovium via extravasation through leaky vasculature and subsequent inflammatory cell-mediated sequestration (ELVIS) effect. A pH-dependent payload release from the nanocarrier was detected in activated macrophages due to ketal hydrolysis under acidic conditions of lysosomes. Nanoparticles also considerably prolonged Dex circulation in plasma in comparison to free Dex sodium phosphate (DSP) that is widely used in the clinic. The $\mathrm{AUC}_{0-\infty}$ of total Dex from SKD-loaded nanoparticles and $2^{\prime}$ NKD-loaded nanoparticles were 17.7-fold and 9.7-fold higher, respectively than that of free DSP. Evaluations of in vivo therapeutic efficacy of nanoparticles revealed a substantial anti-inflammation effect because of inhibition of inflammatory cytokines (TNF- $\alpha$ and IL-1 $\beta$ ), which ultimately, led to cartilage preservation and prevented bone destruction.

\section{Temperature-responsive PNPs}

Temperature-responsive polymers are designed based on their phase-transition behavior in response to changes in temperature. Thermo-responsive behavior of nanocarriers is usually achieved by applying the lower critical solution temperature (LCST) polymers whose solubility behavior is controlled by temperature alterations. LCST is the temperature,below which the 
A

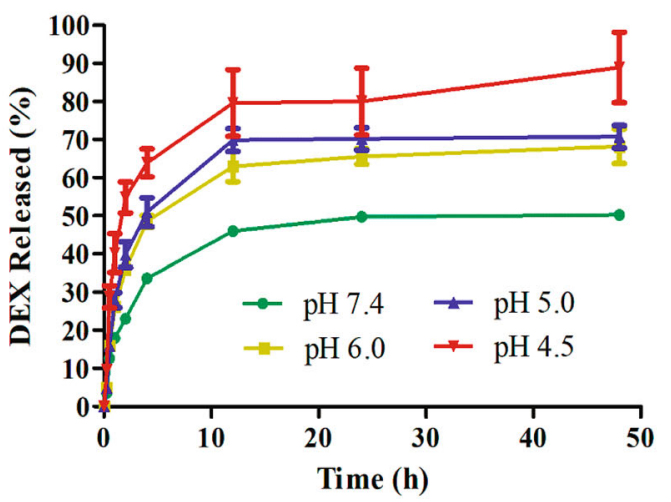

B

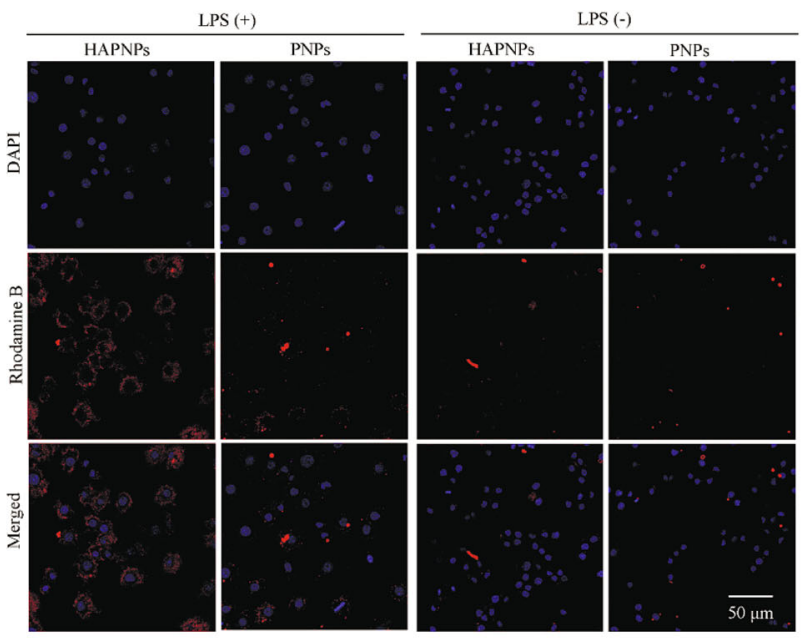

C

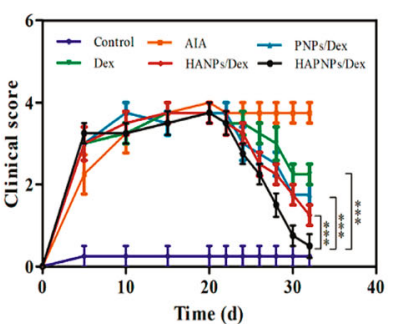

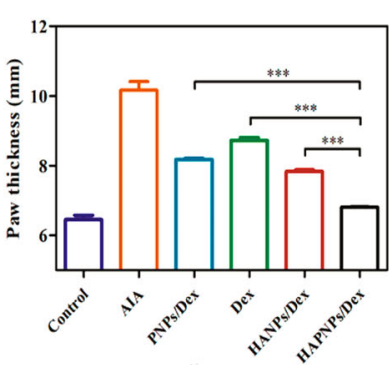

D

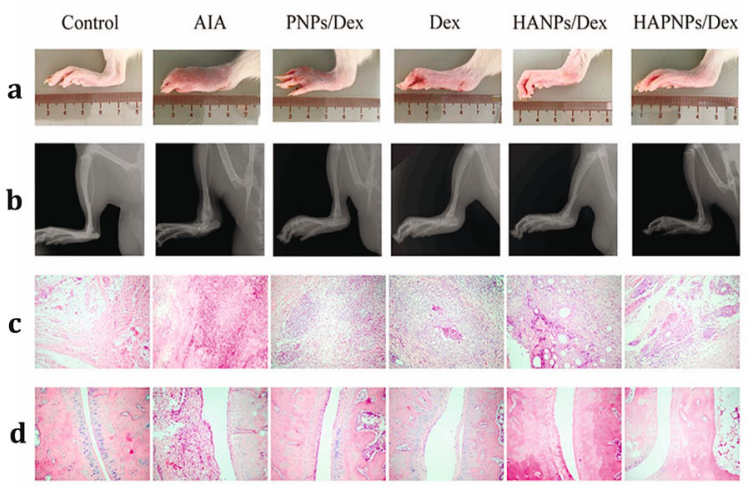

Fig. 4 Experimental outcomes of HAPNPs applied for the treatment of RA. A In vitro drug release profile of HAPNPs/Dex. B Confocal laser scanning microscope images of RAW 264.7 cells after activation by LPS $(+)$ or not $(-)$ incubated with rhodamine B-loaded PNPs and HAPNPs. C Clinical score of RA as a function of days after incubation and hind paw thickness of AIA rats on day 32 after induction. Results presented as mean $\pm \operatorname{SD}\left(n=6,{ }^{* * *} p<0.001\right)$. D Therapeutic effects of HAPNPs/Dex, PNPs/Dex, HANPs/Dex and free Dex in AIA rats. a Photographs of AIA rat paws from the different groups. b Hind paws of AIA rats imaged by X-ray. $\mathbf{c}$ Periarticular soft tissues of hind paws histologically identified by H\&E staining. $\mathbf{d}$ Ankle joints of hind paws in the different group histologically identified by H\&E staining (Yu et al. 2019)

components of a mixture are completely miscible in all proportions. Below LCST, the solubility of polymers with transitional behavior is increased and polymeric components are swollen because of hydrogen bonds formed between water molecules and the polymer functional groups, making them ready to be loaded with drug molecules. Once the temperature is slightly above the LCST, a hydrophilic-hydrophobic transition takes place, and it accompanied by a morphological transition from coil-to-globule. During this change, the hydrogen bonds and the network collapse, and the polymer becomes insoluble, resulting in volumetric shrinkage and squeezing-out of internal water molecules (Karimi et al. 2016b). This transition triggers the release of the encapsulated guest drug molecules (Fig. 8).
Nowadays, hyperthermia is a method applied in the treatment of many diseases, including RA. The idea of the utilization of thermo-sensitive systems for biomedical applications is from the temperature difference between pathological and healthy tissues (Singh and Amiji 2018). Thermal energy can be provided directly, or external heat sources such as NIR are applied indirectly in RA, which both arouses a response of thermosensitive nanomaterials. Usually, the range of temperatures employed is within the $38.5-43^{\circ} \mathrm{C}$ (Karimi et al. 2016a). Stimuli can come from the human body, and local hyperthermia, or hypothermia may arouse a response of thermo-sensitive nanomaterials. Thermoresponsive drug delivery systems can also be designed according to the required application, for instance, to 
A

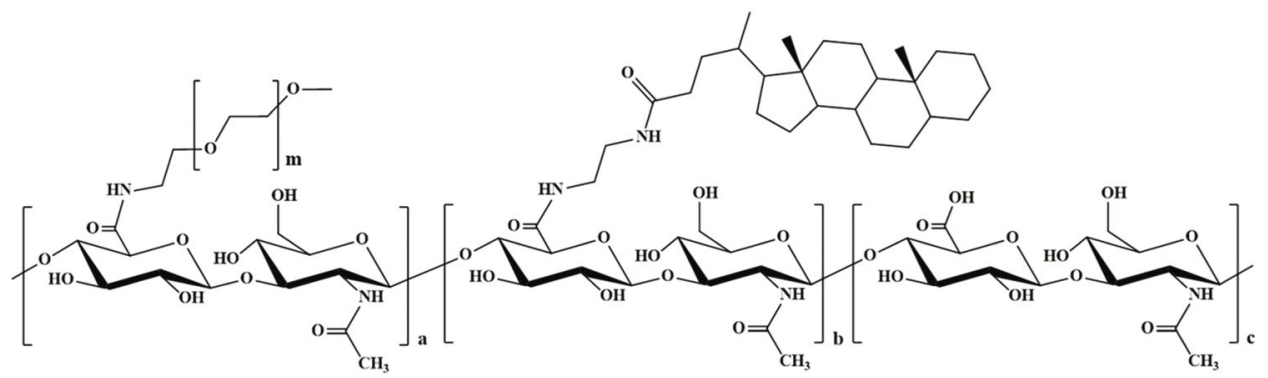

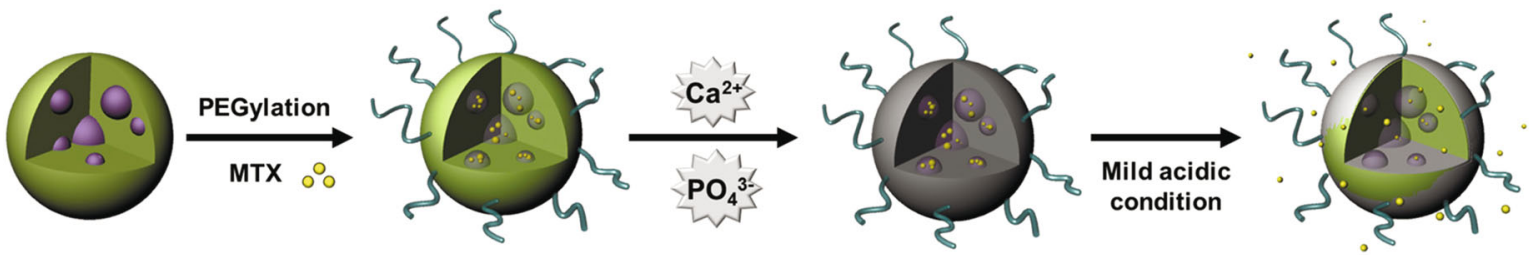

B

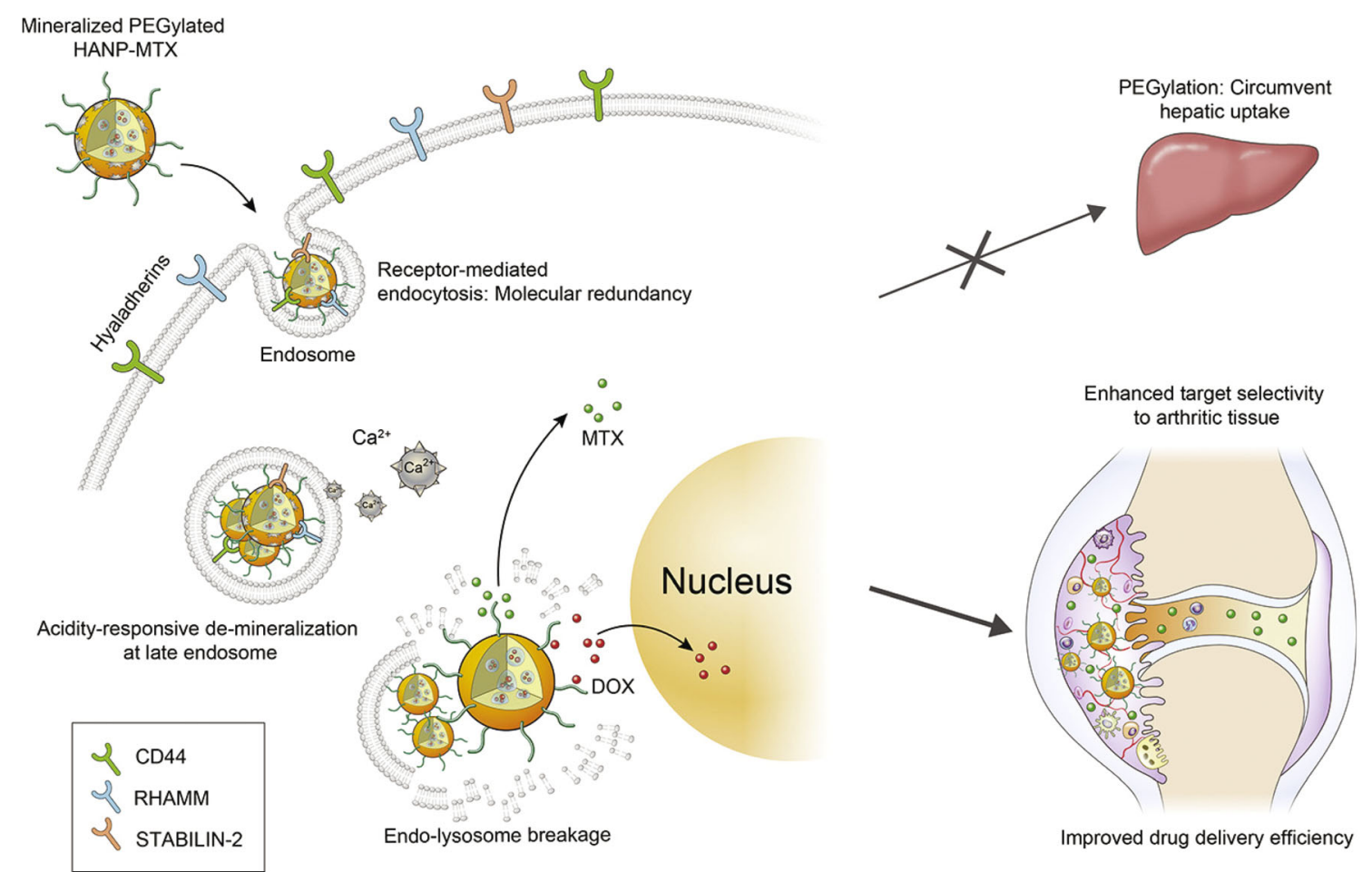

Fig. 5 Synthesis and application of mineralized PEGylated HANP-MTX. A Chemical structure of PEGylated HANPs and diagram showing MTX loading of PEGylated HANPs, followed by calcium phosphate mineralization, which is demineralized and released the drug in the acidic environments. B Schematic presentation of the working mechanism of mineralized PEGylated hyaluronan nanoparticles (MPHANPs) loaded with methotrexate (MTX) or doxorubicin (DOX) (Alam et al. 2017)

achieve temperature-mediated drug release with the accumulation of drugs at the desired biological area. The other advantages of thermo-sensitive polymeric carriers can be attributed to avoidance of using toxic organic solvents during the preparation process, the ability to encapsulate both hydrophilic and lipophilic drug molecules, and sustained release properties. Multiple polymers have been demonstrated for the fabrication of temperature-responsive systems, including $\operatorname{poly}(N$-isopropylacrylamide (PNIPAAm) derivatives, $\operatorname{poly}(N$ - 


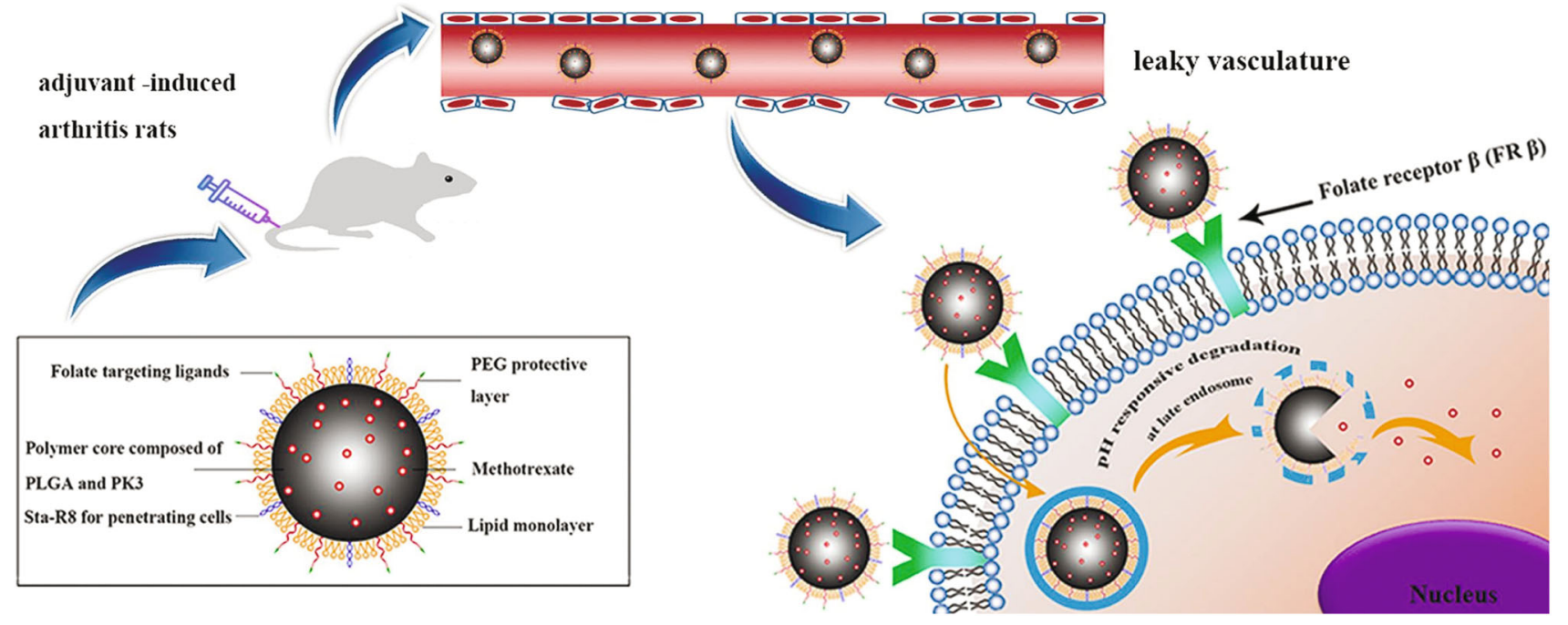

Fig. 6 Schematic presentation of the working mechanism of dual-functional lipid polymeric hybrid pH-responsive nanoparticles decorated with cell-penetrating peptide and folate for therapy against rheumatoid arthritis (Zhao et al. 2018)

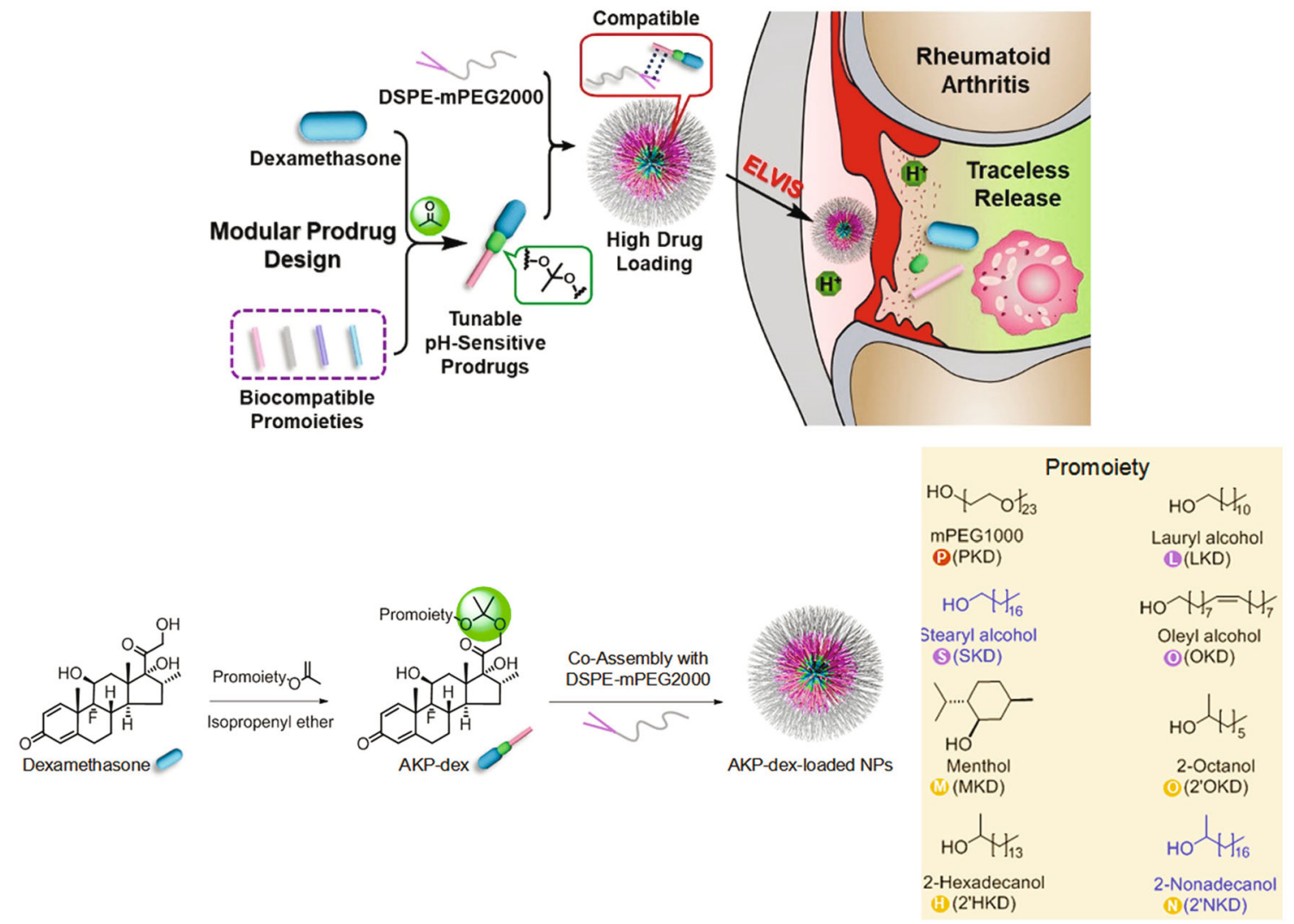

Fig. 7 Schematic representation of Dex-loaded nanoparticles mechanism of action and synthesis route of prodrugs (Xu et al. 2020)

vinylcaprolactam), pluronics (poly(ethylene oxide)poly(propylene oxide) (PEO-PPO)), polysaccharide derivatives, and phosphazene derivatives (Behrens et al. 2014; Beija et al. 2011; Chen et al. 2013; Elluru et al. 2013; Uslu and Güvenaltın 2010).
Up to now, there is few research works published on the subject of temperature-responsive PNPs in the treatment of RA. Researchers are focusing on temperature-response of PNPs aroused by thermo-effect of lightabsorption or magnetic action instead of temperature 
Fig. 8 Mechanism of action of thermo-responsive drug delivery system (Karimi et al. 2016b)

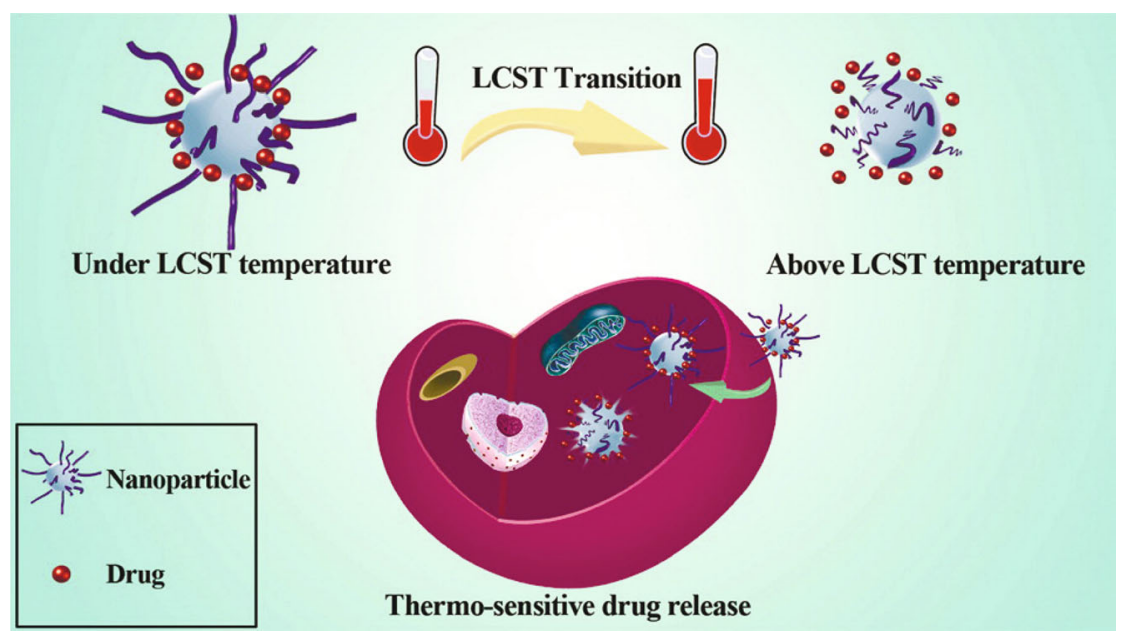

difference between pathological and healthy tissues. However, temperature-responsive PNPs are greatly investigated in anti-cancer therapy, since tumor cells seem to be more sensitive to heat-induced damage than normal cells, which provides sufficient examples and successful new thoughts in the further RA therapy. For instance, Zhang et al. successfully prepared a temperature-responsive PEGylated polyaspartamide derivative (mPEG-PAAHP), which exhibited temperature responsiveness obviously around $25{ }^{\circ} \mathrm{C}$. The formulated PTXloaded nanoparticles showed high drug loading capacity, good stability, and substantial anti-cancer effect against HeLa cells (Zhang and Jiang 2019).

\section{Photo-responsive PNPs}

The strategy of photo-responsive drug delivery is based on light-absorption properties of polymers that undergo phase transition upon light irradiation. Most chemistries respond mainly to ultraviolet (UV), visible, and nearinfrared (NIR) lights. These polymeric materials are very attractive for their possibility to control the spatial and temporal triggering of drug release, as well as for their water solubility, biodegradability, and biocompatibility. According to the required application, two main strategies can be used: either a one-time or repeatable on-off drug release. This could be possible due to the ability of some materials to undergo irreversible structural modifications in response to exposure to light, while others can return to the initial state after the trigger is removed. For example, azobenzene group and its derivatives can be reversibly isomerized from transto cis- on ultraviolet-visible light, and from cis- to transby shining light in the visible region, provides release photoregulated control of payload (Lu et al. 2008).
Some photo-sensitive polymers that are now largely employed in the field of nanomedicine with a potential in the treatment of RA in the future are presented in Table 3. However, only NIR light penetrates more deeply into tissues, which along with low harmful effects to cells, makes it suitable for RA therapy. It is also indicated that RA is characterized by synovial inflammation of the joints within the penetration depth of NIR, which makes possible the applying of a photo-responsive method (Lee et al. 2013).

Fomina et al. synthesized degradable nanoparticles composed of photo-sensitive polymers with a self-immolative quinone-methide system (Fomina et al. 2010). The novel photo-sensitive nanoparticles are capable of controlled triggered burst release of small hydrophobic molecules (Fig. 9). Thus, the versatile design of this system is supposed to allow the triggering group to be sensitive to internal or remote stimuli, which has great potential for RA treatment. In another work, authors reported a polymeric material that was disassembled in response to biological benign levels of NIR irradiation upon two-photon absorption. The design relied on the photolysis of the multiple pendants 4-bromo7-hydroxycoumarin protecting groups, which further triggered a cascade of cyclization and rearrangement reactions leading to the degradation of the polymer backbone (Fomina et al. 2011). Furthermore, this polymer is well tolerated by cells both before and after degradation. These results demonstrate that the potential NIR-sensitive polymer may be employed for in vivo applications, such as in the treatment of RA. Until now, the versatile design of photo-responsive polymers is under investigation while specific studies on RA in the use of photo-responsive PNPs are greatly insufficient. 
Table 3 Examples of photo-sensitive polymeric materials, which can be applied for RA therapy

\begin{tabular}{|c|c|c|c|c|}
\hline Polymeric material & $\begin{array}{l}\text { Size of } \\
\text { nanoparticles } \\
(\mathrm{nm})\end{array}$ & Stimulus & $\begin{array}{l}\text { Applied light } \\
\text { wavelength }(\mathrm{mn})\end{array}$ & References \\
\hline $\begin{array}{l}\text { Quinone-methide backbone-diamine spacer 4,5-dime- } \\
\text { thoxy-2-nitrobenzyl alcohol }\end{array}$ & 170 & $\begin{array}{l}\text { Light (self- } \\
\text { immolative } \\
\text { system) }\end{array}$ & $350 ; 750$ & $\begin{array}{l}\text { Fomina et al } \\
\quad(2010)\end{array}$ \\
\hline $\begin{array}{l}o \text {-Nitrobenzyl/methacrylate- } \\
\text { functionalized poly(ethylenimine) }\end{array}$ & 160 & $\begin{array}{l}\text { Light (photolytic } \\
\text { degradation) }\end{array}$ & 365 & $\begin{array}{l}\text { Kim et al. } \\
\quad(2010)\end{array}$ \\
\hline $\begin{array}{l}\text { Chitosan hydrochloride 4-oxo-4-(pyren-4-ylmethoxy) } \\
\text { butanoic acid }\end{array}$ & 100 & $\begin{array}{l}\text { Light (photolytic } \\
\text { disassembly) }\end{array}$ & 1200 & $\begin{array}{l}\text { Cui et al. } \\
\text { (2011) }\end{array}$ \\
\hline 4'-Azobenzene dibenzoyl chloride/triethanolamine & $20-100$ & $\begin{array}{l}\text { Light (trans/cis } \\
\quad \text { isomerization) }\end{array}$ & 316 & $\begin{array}{l}\text { Shen et al. } \\
\quad \text { (2011) }\end{array}$ \\
\hline 2-Nitrophenylethylene glycol/diamine & $217-358$ & $\begin{array}{l}\text { Light (photolytic } \\
\text { degradation) }\end{array}$ & 550 & $\begin{array}{l}\text { Lv et al. } \\
\quad(2012)\end{array}$ \\
\hline
\end{tabular}

\section{Redox- and enzyme-responsive PNPs}

Redox-sensitive nanomaterials are another emerging field for the design of novel drug delivery systems. A great interest in this type of system arises from the difference in redox potential between the oxidizing and reducing space. A number of studies have demonstrated the role of reactive oxygen species (ROS) in the pathogenesis of inflammatory chronic arthropathies, such as RA. ROS are produced mainly during oxidative phosphorylation and can also be generated by activated phagocytic cells during an oxidative burst. They serve as an important intracellular signal that enhances the inflammatory response (Abbas and Monireh 2008; Fonseca et al. 2019; Khojah et al. 2016). The elevated level of ROS in cancer cells has been widely exploited as the main trigger for the drug release from sensitive delivery systems. For example, the polymers with introduced ROS-sensitive thioketal units or Te-, Se-, B-based linkers in their monomers were used as building blocks for the preparation of responsive nanoparticles. These systems exhibited enhanced selective accumulation at the tumor site and sustained drug release after thioketal groups had been cleaved by ROS (Chen et al. 2019a; Jin et al. 2019; Wilson et al. 2010). The strategies of cancer treatment by ROS-sensitive nanoparticles also can be effectively applied in RA therapy, thus, creating new opportunities to improve the therapeutic outcome by precise control of the system degradation and drug release rate. However, the type of cleavable moiety, its sensitivity, and placement in the delivery system greatly influence the kinetics of payload release. It is also very important to ensure that the degraded units are still biocompatible and can be safely eliminated from the body as non-toxic fragments.

Enzymes participate in all biological and metabolic processes. They are highly selective and efficient catalysts for organic biochemical reactions. Enzyme-responsive PNPs may provide personalized therapy according to alterations in disease expression in the future. An enhanced expression profile of specific enzymes, such as proteases, phospholipases, or glycosidases observed in pathological situations, such as cancer or inflammation, can be used for enzymetriggered drug release with an accumulation of drugs at the targeted biological area (De La Rica et al. 2012). The design principle of enzyme-mediated nanoparticles is similar to other stimuli, the use of cleavable linkers, to embed them in the polymer backbone and then formulate a drug-loaded carrier. Up to now, some advances in the use of redox- and enzyme-responsive PNPs that are applied in anti-cancer therapy have been reported (Huo et al. 2014; Kuang et al. 2016). Several redoxresponsive polymers have been designed and successfully applied in controlled drug release. However, to the knowledge of the authors, there is no such application in the treatment of RA. Redox- and enzyme-responsive nanomaterials are waiting for being explored in the field of RA. Some potential redox- and enzyme-sensitive polymeric nanomaterials for RA are listed here, which now are being used for anti-cancer therapy (Table 4).

\section{Multistimuli responsive drug delivery}

Multistimuli-responsive drug delivery systems are sensitive to more than one stimulus. In the realm of cancer drug delivery, numerous stimuli-responsive carrier 

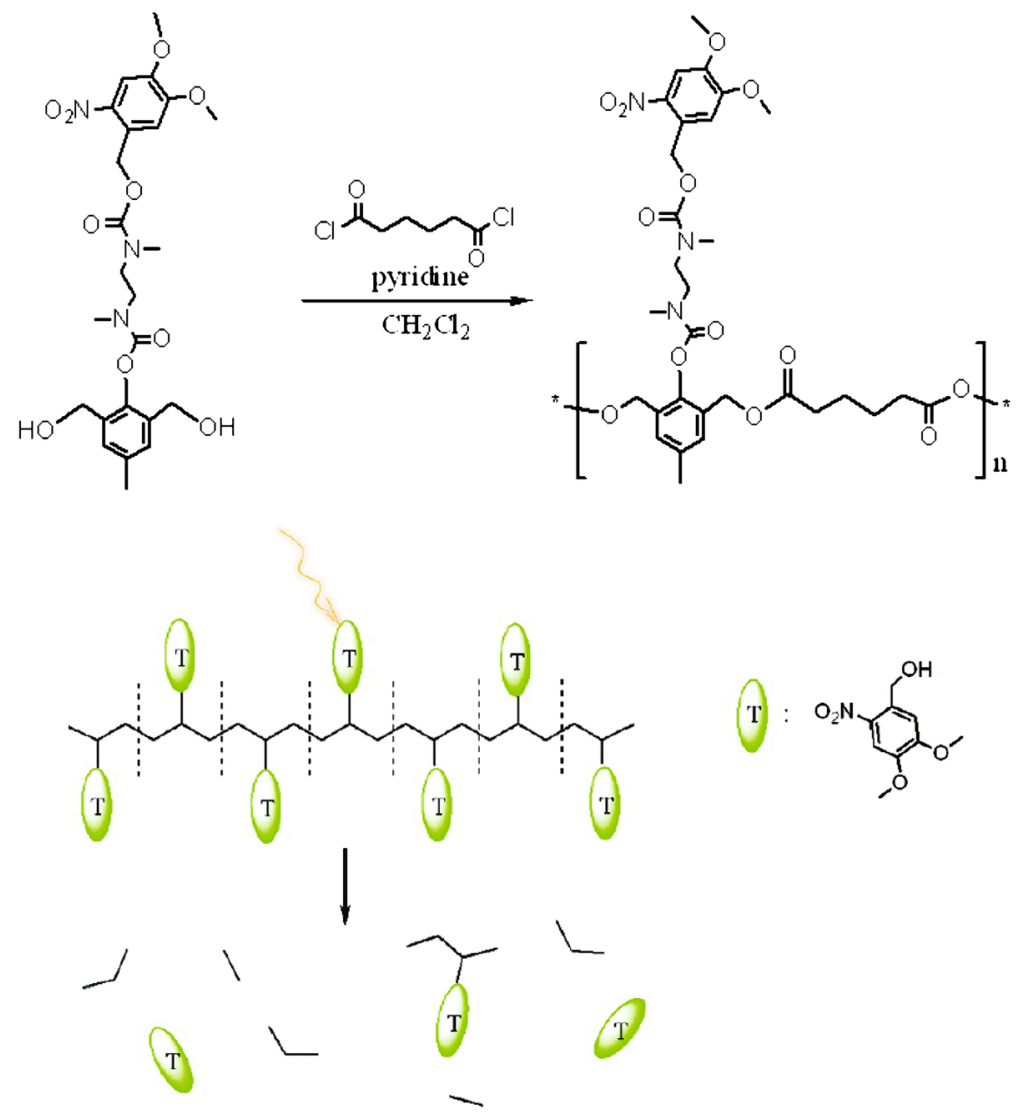

Fig. 9 Synthesis route of light-sensitive degradable polymer containing a quinone-methide self-immolative moiety and its subsequent degradation upon irradiation (Fomina et al. 2010)

systems, in the form of conjugates, dendrimers, liposomes, and micelles, have been developed (Heidarli et al. 2017). Although the same potential also exists for RA treatment, few single stimuli drug delivery systems have been reported. In certain pathological conditions, including inflammation or cancer, the coexistence of a $\mathrm{pH}$ gradient and an oxidative environment can be observed. Under this conditions $\mathrm{pH}$ and redox responsiveness can be used in combination. For instance, conjugation of doxorubicin and antisense-bcl2 oligonucleotide to a four-arm poly(ethylene glycol) with redoxreducible and acid-cleavable linkers resulted in enhanced cancer cell apoptosis (Yoon et al. 2013). In another study, a highly packed interlayer-crosslinked micelle with reduction and $\mathrm{pH}$ dual sensitivity demonstrated triggered nanocarrier disassembly and a burst of payload release in a reductant-rich environment, resulting in an improvement of the therapeutic index of the loaded drug (Dai et al. 2011). Dual responsiveness to $\mathrm{pH}$ and temperature of ionically self-assembled nanoparticles and liposomes showed an improved drug release activation (Cui et al. 2012; Ta et al. 2010). Light- sensitivity can also be combined with $\mathrm{pH}$ responsiveness by exploiting the resonance surface properties of palladium and silver (Fang et al. 2012). Examples of other systems have demonstrated sensitivity to temperature and magnetic field for MTX delivery (Baeza et al. 2012); to light and reducing environment to control the release behavior from block copolymer micelles (Han et al. 2012), and to ultrasounds and enzymes to increase drug release from bubble liposomes (Nahire et al. 2012).

In addition to $\mathrm{pH}-$, temperature-, photo-, and redoxresponsive of nanomaterials, other stimuli from inorganic agents are always combined for the sake of maximizing therapeutic efficiency.

Conventional therapy has a severe drawback of short biological half-life in the development of a drug delivery system. A high dose is needed to assure therapeutic efficiency while it may simultaneously lead to severe side effects. Magnetic nanocarriers can be engineered for local drug delivery at inflammatory sites under the guidance of a magnetic field, providing sufficient therapeutic concentrations with a reduced incidence of 
Table 4 Examples of potential redox- and enzyme-sensitive polymeric materials, which can be applied for RA therapy

\begin{tabular}{llll}
\hline Polymeric material & $\begin{array}{l}\text { Size of nanoparticle } \\
(\mathrm{nm})\end{array}$ & Stimuli & References \\
\hline Poly(ethylene glycol)-b-poly(lactic acid) & 374 & Redox (disulfide bond) & $\begin{array}{c}\text { Song } \text { et al. } \\
(2011)\end{array}$ \\
$\begin{array}{l}\text { Poly(acrylamide)-poly(methacrylamide)- } N, N \text { '-bis- } \\
\text { (acryloyl)cystamine }\end{array}$ & 11.3 & Redox (disulfide bond) & $\begin{array}{c}\text { Zhao et al. } \\
(2011)\end{array}$ \\
$\begin{array}{l}\text { Dimethylaminoethyl methacrylate/ } N, N \text {-bis-(acryloyl) } \\
\text { cystamine }\end{array}$ & 35 & Redox (disulfide bond) & $\begin{array}{c}\text { Boyer } \text { et al. } \\
(2009)\end{array}$ \\
$N$-(3-aminopropyl) methacrylamide)/acrylamide & $20-45$ & Enzyme (protease- & Wen et al. (2011) \\
\hline
\end{tabular}

unwanted side effects (Polyak and Friedman 2009). Arias et al. developed magnetic responsive iron/ethylcellulose (core/shell) nanoparticles loaded with diclofenac sodium for arthritis treatment (Arias et al. 2009).

Categories of magnetic core-shell drug carriers are based on a core mainly containing $\mathrm{Fe}_{2} \mathrm{O}_{3}$ and $\mathrm{Fe}_{3} \mathrm{O}_{4}$, and different shells such as poly(lactic-co-glycolic acid), poly(vinylpyrrolidone), chitosan, silica, calcium silicate, metal, and lipids (Albinali et al. 2019). Thus, a stimuliresponsive polymer can be as shell encapsulating a magnetic core to obtain more specific targeting and higher release rate. Besides, iron oxide $\left(\mathrm{Fe}_{3} \mathrm{O}_{4}\right)$ nanoparticles exhibited absorption in the NIR region, which implies their potential role in photothermal therapy. Zhang et al. indicated that $\mathrm{Fe}_{3} \mathrm{O}_{4}$, easily fabricated within the size range of $50-400 \mathrm{~nm}$, has a great potential in ablating activated or hyperplastic cells in RA therapy (Zhang et al. 2018). Iron oxide is an ideal candidate for investigating the effect of nanoparticles size on distribution and multistimuli treatment of RA.

Gold $(\mathrm{Au})$ is currently capturing huge interests in the field of nanomedicine since gold nanoparticles $\mathrm{CAu}$ nanoparticles) demonstrate attractive optical properties, modifiable surface for target molecules or specific biomarkers, and tunable absorption in both visible and NIR regions (Vats et al. 2017). Au nanoparticles have various applications including biomolecular ultrasensitive detection, killing cancer cells by hyperthermal treatment, labeling for cells and proteins, and delivering therapeutic agents within cells (Singh et al. 2018). Au nanoparticles that absorb NIR and convert it into cytotoxic heat can provide effective photothermal therapeutic effect by accelerating drug release. More importantly, Au nanoparticles are tending to be a multifunctional platform when other stimuli-responsive modes are set. Lima et al. designed a novel multi-drug theranostic system for rheumatoid arthritis treatment, where MTX and Au nanoparticles were incorporated into the pegylated-poly(DL-lactic-co-glycolic acid) (MTXPEG-PLGA-Au) nanospheres (Lima and Reis 2015). In their work, in vitro, drug release assays revealed that the PEG-PLGA-Au nanospheres could release MTX in a temperature- and $\mathrm{pH}$-responsive mode. In addition, the presence of $\mathrm{Au}$ nanoparticles significantly improved the MTX release at photothermal temperature $\left(42^{\circ} \mathrm{C}\right)$ and under acidic $\mathrm{pH}$ conditions. Kim et al. have developed MTX-loaded poly(lactic-co-glycolic acid) (PLGA) Au/Fe/ $\mathrm{Au}$ half-shell nanoparticles conjugated with arginine-glycine-aspartic acid (Fig. 10), which can be applied for magnetic targeted chemo-photothermal treatment, and in vivo multimodal imaging of RA (Kim et al. 2015). When combined with consecutive NIR irradiation and external magnetic field application, these nanoparticles provide enhanced therapeutic effects with an MTX dosage of only $0.05 \%$ compared with free MTX therapy in the treatment of RA.

\section{SUMMARY AND PERSPECTIVE}

In the past few decades, NMs formulated from stimuliresponsive polymers have made a great contribution to RA treatment. It was proven that the precise drug delivery to the inflammatory joints could significantly improve the therapeutic index and reduce adverse effects associated with the systemic toxicity of anti-RA drugs. The fabrication of NMs sensitive to exogenous or endogenous stimuli may represent an attractive alternative to targeted drug delivery. The wide range of triggers are able to promote the payload release at the desired area and right time, and the variety of responsive materials, which can be assembled in diverse architectures, provide great flexibility in the design of stimuli-responsive systems. 

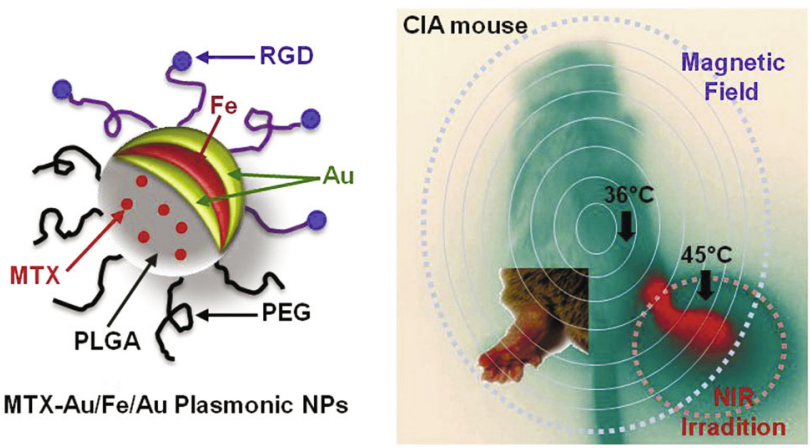

Fig. 10 Multifunctional nanoparticle stimulated under NIR irradiation and external magnetic field application. A Schematic depiction of a MTX-loaded poly(lactic-co-glycolic acid) (PLGA) gold $(\mathrm{Au}) /$ iron $(\mathrm{Fe}) /$ gold $(\mathrm{Au})$ half-shell nanoparticles conjugated with target moieties (PEG). B Under NIR irradiation, the release of therapeutic agent (MTX) from PLGA accelerated due to local heat which is generated by Au half-shells. And Fe half-shell enables in vivo T2-magnetic resonance (MR) imaging in addition to NIR absorbance imaging. Besides, the retention of nanoparticles which have delivered to inflammation region in CIA mice can be enhanced under external magnetic environment (Kim et al. 2015)

However, despite the significant advancement of stimuli-responsive polymers in the area of drug delivery, there are still a number of concerns that remain to be addressed. Safety issues are considered to be one of the most limiting factors in the medical application. The toxicity of stimuli-responsive systems is multi-factorial and associated with such factors as materials composition, physicochemical features, route of administration, and dosage. Thus, the key point is finding the balance between benefit and risk according to the intended medical use. Furthermore, the lack of degradability or insufficient biocompatibility of many available stimuliresponsive systems significantly reduces their chances of reaching clinics, since it is extremely important that nanocarriers can undergo safe elimination that prevents their accumulation in the body. Another concern is related to the control of the physicochemical properties of nanocarriers' building blocks that can affect their stimuli-responsiveness. The high sensitivity of these systems to the changes of $\mathrm{pH}$, temperature, or redox potential is not straightforward to achieve, and issues associated with the penetration depth of external stimuli need to be solved. In order to take advantage of nanotechnology and attain greater therapeutic effect, such properties of drug delivery systems as particle size, surface charge, loading capacity, stability during blood circulation, response time, release kinetics, etc. should also be taken into account.

Achieving effective drug delivery, avoiding intravenous or intra-articular injections during RA therapy, is now one of the most considerable aspects. Since oral administration is the most convenient and commonly used drug delivery route, it has a crucial importance to find methods to improve the bioavailability of drug delivery systems, and thus, overcome issues associated with invasive administration routes. Moreover, the higher bioavailability along with improved treatment efficacy by drug-bearing nanocarriers can lower the medication amount and administration frequency, which is always being pursued. Transdermal delivery represents an attractive alternative to oral drug delivery in the affected joints. This administration way can be used when there is a significant first-pass drug metabolism in the liver. Moreover, the transdermal delivery can provide drug release for a long period. However, the main drawback is that only a limited number of drugs are suitable for this administration route. For most stimuli-responsive systems, the complex architectural design and difficulties in the scaling-up of their synthesis can hinder their translation to the industrial scale. In this regard, the more facile fabrication of polymer NMs is of importance for further industrial translation. More simple fabrication process and fewer components needed could realize more possibilities of polymer NMs translated to industry.

Acknowledgements The authors thank the financial support under the National Natural Science Foundation of China (31971302 and 51903062), Natural Science Foundation of Guangdong Province of China (2019A1515011597 and 2018A030313588) and Project of Educational Commission of Guangdong Province of China (2017KQNCX163).

\section{Compliance with Ethical Standards}

Conflict of interest Yingsi Xie, Ruslan G. Tuguntaev, Cong Mao, Haoting Chen, Ying Tao, Shixiang Wang, Bin Yang, and Weisheng Guo declare that they have no conflict of interest.

Human and animal rights and informed consent This article does not contain any studies with human or animal subjects performed by any of the authors.

Open Access This article is licensed under a Creative Commons Attribution 4.0 International License, which permits use, sharing, adaptation, distribution and reproduction in any medium or format, as long as you give appropriate credit to the original author(s) and the source, provide a link to the Creative Commons licence, and indicate if changes were made. The images or other third party material in this article are included in the article's Creative Commons licence, unless indicated otherwise in a credit line to the material. If material is not included in the article's Creative Commons licence and your intended use is not permitted by statutory regulation or exceeds the permitted use, you will need to obtain permission directly from the copyright holder. To view a copy of this licence, visit http://creativecommons.org/ licenses/by/4.0/. 


\section{References}

Abbas M, Monireh M (2008) The role of reactive oxygen species in immunopathogenesis of rheumatoid arthritis. Iran J Allergy Asthma Immunol 7(4):195-202

Alam MM, Han HS, Sung S, Kang JH, Sa KH, Al Faruque H, Hong J, Nam EJ, San Kim I, Park JH (2017) Endogenous inspired biomineral-installed hyaluronan nanoparticles as $\mathrm{pH}$-responsive carrier of methotrexate for rheumatoid arthritis. J Control Release 252:62-72

Albinali KE, Zagho MM, Deng Y, Elzatahry AA (2019) A perspective on magnetic core-shell carriers for responsive and targeted drug delivery systems. Int J Nanomed 14:1707

Aletaha D, Smolen JS (2018) Diagnosis and management of rheumatoid arthritis: a review. JAMA 320(13):1360-1372

Arias JL, López-Viota M, López-Viota J, Delgado ÁV (2009) Development of iron/ethylcellulose (core/shell) nanoparticles loaded with diclofenac sodium for arthritis treatment. Int J Pharm 382(1-2):270-276

Baeza A, Guisasola E, Ruiz-Hernandez E, Vallet-Regí M (2012) Magnetically triggered multidrug release by hybrid mesoporous silica nanoparticles. Chem Mater 24(3):517-524

Behrens MA, Bergenholtz J, Pedersen JS (2014) TemperatureInduced attractive interactions of PEO-containing block copolymer micelles. Langmuir 30(21):6021-6029

Beija M, Marty J-D, Destarac M (2011) Thermoresponsive poly $(N$ vinyl caprolactam)-coated gold nanoparticles: sharp reversible response and easy tunability. Chem Commun 47(10):2826-2828

Borregaard N, Herlin T (1982) Energy metabolism of human neutrophils during phagocytosis. J Clin Investig 70(3):550-557

Boyer C, Liu J, Bulmus V, Davis TP (2009) RAFT polymer endgroup modification and chain coupling/conjugation via disulfide bonds. Aust J Chem 62(8):830-847

Chatterjee S, Hui C-L (2019) Review of stimuli-responsive polymers in drug delivery and textile application. Molecules 24(14):2547

Chen M-C, Mi F-L, Liao Z-X, Hsiao C-W, Sonaje K, Chung M-F, Hsu L-W, Sung H-W (2013) Recent advances in chitosan-based nanoparticles for oral delivery of macromolecules. Adv Drug Deliv Rev 65(6):865-879

Chen B, Zhang Y, Ran R, Wang B, Qin F, Zhang T, Wan G, Chen H, Wang Y (2019a) Reactive oxygen species-responsive nanoparticles based on a thioketal-containing poly ( $\beta$-amino ester) for combining photothermal/photodynamic therapy and chemotherapy. Polym Chem 10(34):4746-4757

Chen M, Amerigos JCK, Su Z, Guissi NEI, Xiao Y, Zong L, Ping Q (2019b) Folate receptor-targeting and reactive oxygen species-responsive liposomal formulation of methotrexate for treatment of rheumatoid arthritis. Pharmaceutics 11(11):582

Cui W, Lu X, Cui K, Wu J, Wei Y, Lu Q (2011) Photosensitive nanoparticles of chitosan complex for controlled release of dye molecules. Nanotechnology 22(6):065702

Cui W, Lu X, Cui K, Niu L, Wei Y, Lu Q (2012) Dual-responsive controlled drug delivery based on ionically assembled nanoparticles. Langmuir 28(25):9413-9420

Dai J, Lin S, Cheng D, Zou S, Shuai X (2011) Interlayer-crosslinked micelle with partially hydrated core showing reduction and $\mathrm{pH}$ dual sensitivity for pinpointed intracellular drug release. Angew Chem Int Ed 50(40):9404-9408

De La Rica R, Aili D, Stevens MM (2012) Enzyme-responsive nanoparticles for drug release and diagnostics. Adv Drug Deliv Rev 64(11):967-978
Deane KD, Demoruelle MK, Kelmenson LB, Kuhn KA, Norris JM, Holers VM (2017) Genetic and environmental risk factors for rheumatoid arthritis. Best Pract Res Clin Rheumatol 31(1):3-18

Duong HT, Jung K, Kutty SK, Agustina S, Adnan NNM, Basuki JS, Kumar N, Davis TP, Barraud N, Boyer C (2014) Nanoparticle (star polymer) delivery of nitric oxide effectively negates Pseudomonas aeruginosa biofilm formation. Biomacromol 15(7):2583-2589

Elluru M, Ma H, Hadjiargyrou M, Hsiao BS, Chu B (2013) Synthesis and characterization of biocompatible hydrogel using Pluronics-based block copolymers. Polymer 54(8):2088-2095

Fang W, Yang J, Gong J, Zheng N (2012) Photo-and pH-triggered release of anticancer drugs from mesoporous silica-coated Pd@ Ag nanoparticles. Adv Funct Mater 22(4):842-848

Farr M, Garvey K, Bold A, Kendall M, Bacon P (1985) Significance of the hydrogen ion concentration in synovial fluid. Clin Exp Rheumatol 3:99-104

Firestein GS, McInnes IB (2017) Immunopathogenesis of rheumatoid arthritis. Immunity 46(2):183-196

Fomina N, McFearin C, Sermsakdi M, Edigin O, Almutairi A (2010) UV and near-IR triggered release from polymeric nanoparticles. J Am Chem Soc 132(28):9540-9542

Fomina N, McFearin CL, Sermsakdi M, Morachis JM, Almutairi A (2011) Low power, biologically benign NIR light triggers polymer disassembly. Macromolecules 44(21):8590-8597

Fonseca LJS, Nunes-Souza V, Goulart MOF, Rabelo LA (2019) Oxidative stress in rheumatoid arthritis: what the future might hold regarding novel biomarkers and add-on therapies. Oxid Med Cell Longevity 2019:7536805

Ganta S, Devalapally H, Shahiwala A, Amiji M (2008) A review of stimuli-responsive nanocarriers for drug and gene delivery. J Control Release 126(3):187-204

Gaspar VM, Marques JG, Sousa F, Louro RO, Queiroz JA, Correia IJ (2013) Biofunctionalized nanoparticles with pH-responsive and cell penetrating blocks for gene delivery. Nanotechnology 24(27):275101

Geborek P, Saxne T, Pettersson H, Wollheim F (1989) Synovial fluid acidosis correlates with radiological joint destruction in rheumatoid arthritis knee joints. J Rheumatol 16(4):468-472

Goldie I, Nachemson A (1969) synovial pH in rheumatoid kneejoints. I. The effect of synovectomy. Acta Orthop Scand 40(5):634-641

Guo Q, Wang Y, Xu D, Nossent J, Pavlos NJ, Xu J (2018) Rheumatoid arthritis: pathological mechanisms and modern pharmacologic therapies. Bone Res 6:15

Han D, Tong X, Zhao Y (2012) Block copolymer micelles with a dual-stimuli-responsive core for fast or slow degradation. Langmuir 28(5):2327-2331

Heidarli E, Dadashzadeh S, Haeri A (2017) State of the art of stimuli-responsive liposomes for cancer therapy. Iran J Pharm Res 16(4):1273-1304

Huo M, Yuan J, Tao L, Wei Y (2014) Redox-responsive polymers for drug delivery: from molecular design to applications. Polym Chem 5(5):1519-1528

Indermun S, Govender M, Kumar P, Choonara YE, Pillay V (2018) Stimuli-responsive polymers as smart drug delivery systems: classifications based on carrier type and triggered-release mechanism. In: Makhlouf ASH, Abu-Thabit NY (eds) Stimuliresponsive polymers as smart drug delivery systems: classifications based on carrier type and triggered-release mechanism. Elsevier, Amsterdam, pp 43-58

Jain M, Attur M, Furer V, Todd J, Ramirez R, Lock M, Lu QA, Abramson SB, Greenberg JD (2015) Increased plasma IL-17F levels in rheumatoid arthritis patients are responsive to 
methotrexate, anti-TNF, and T cell costimulatory modulation. Inflammation 38(1):180-186

James HP, John R, Alex A, Anoop K (2014) Smart polymers for the controlled delivery of drugs-a concise overview. Acta Pharm Sin B 4(2):120-127

Jin H, Zhu T, Huang X, Sun M, Li H, Zhu X, Liu M, Xie Y, Huang W, Yan D (2019) ROS-responsive nanoparticles based on amphiphilic hyperbranched polyphosphoester for drug delivery: light-triggered size-reducing and enhanced tumor penetration. Biomaterials 211:68-80

Jung J, Lee IH, Lee E, Park J, Jon S (2007) pH-sensitive polymer nanospheres for use as a potential drug delivery vehicle. Biomacromol 8(11):3401-3407

Karimi M, Eslami M, Sahandi-Zangabad P, Mirab F, Farajisafiloo N, Shafaei Z, Ghosh D, Bozorgomid M, Dashkhaneh F, Hamblin MR (2016a) pH-Sensitive stimulus-responsive nanocarriers for targeted delivery of therapeutic agents. Wiley Interdiscip Rev Nanomed Nanobiotechnol 8(5):696-716

Karimi M, Sahandi Zangabad P, Ghasemi A, Amiri M, Bahrami M, Malekzad H, Ghahramanzadeh Asl H, Mahdieh Z, Bozorgomid M, Ghasemi A (2016b) Temperature-responsive smart nanocarriers for delivery of therapeutic agents: applications and recent advances. ACS Appl Mater Interfaces $8(33): 21107-21133$

Keffer J, Probert L, Cazlaris H, Georgopoulos S, Kaslaris E, Kioussis D, Kollias G (1991) Transgenic mice expressing human tumour necrosis factor: a predictive genetic model of arthritis. EMBO J 10(13):4025-4031

Khojah HM, Ahmed S, Abdel-Rahman MS, Hamza A-B (2016) Reactive oxygen and nitrogen species in patients with rheumatoid arthritis as potential biomarkers for disease activity and the role of antioxidants. Free Radic Biol Med 97:285-291

Kim MS, Gruneich J, Jing H, Diamond SL (2010) Photo-induced release of active plasmid from crosslinked nanoparticles: o-nitrobenzyl/methacrylate functionalized polyethyleneimine. J Mater Chem 20(17):3396-3403

Kim HJ, Lee S-M, Park K-H, Mun CH, Park Y-B, Yoo K-H (2015) Drug-loaded gold/iron/gold plasmonic nanoparticles for magnetic targeted chemo-photothermal treatment of rheumatoid arthritis. Biomaterials 61:95-102

Kuang T, Liu Y, Gong T, Peng X, Hu X, Yu Z (2016) Enzymeresponsive nanoparticles for anticancer drug delivery. Curr Nanosci 12(1):38-46

Lee SM, Kim HJ, Ha YJ, Park YN, Lee SK, Park YB, Yoo KH (2013) Targeted chemo-photothermal treatments of rheumatoid arthritis using gold half-shell multifunctional nanoparticles. ACS Nano 7(1):50-57

Lima SAC, Reis S (2015) Temperature-responsive polymeric nanospheres containing methotrexate and gold nanoparticles: a multi-drug system for theranostic in rheumatoid arthritis. Colloids Surf B 133:378-387

Liu R, Li D, He B, Xu X, Sheng M, Lai Y, Wang G, Gu Z (2011) Antitumor drug delivery of $\mathrm{pH}$-sensitive poly (ethylene glycol)poly (L-histidine-)-poly (L-lactide) nanoparticles. J Control Release 152(1):49-56

Liu J, Duong H, Whittaker MR, Davis TP, Boyer C (2012) Synthesis of functional core, star polymers via RAFT polymerization for drug delivery applications. Macromol Rapid Commun 33(9):760-766

Liu L, Hu F, Wang H, Wu X, Eltahan AS, Stanford S, Bottini N, Xiao H, Bottini M, Guo W (2019) Secreted protein acidic and rich in cysteine mediated biomimetic delivery of methotrexate by albumin-based nanomedicines for rheumatoid arthritis therapy. ACS Nano 13(5):5036-5048
Lopes JR, Santos G, Barata P, Oliveira R, Lopes CM (2013) Physical and chemical stimuli-responsive drug delivery systems: targeted delivery and main routes of administration. Curr Pharm Des 19(41):7169-7184

Lu J, Choi E, Tamanoi F, Zink JI (2008) Light-activated nanoimpeller-controlled drug release in cancer cells. Small 4(4):421-426

Lv C, Wang Z, Wang P, Tang X (2012) Photodegradable polyurethane self-assembled nanoparticles for photocontrollable release. Langmuir 28(25):9387-9394

McInnes IB, O’Dell JR (2010) State-of-the-art: rheumatoid arthritis. Ann Rheum Dis 69(11):1898-1906

McInnes IB, Schett G (2017) Pathogenetic insights from the treatment of rheumatoid arthritis. Lancet 389(10086):2328-2337

Menkin V (1956) Biology of inflammation. Science 123:527-534

Moon SJ et al. (2020) pH-Sensitive Polymeric Micelles as the Methotrexate Carrier for Targeting Rheumatoid Arthritis Macromolecular Research 28:99-102

Mura S, Nicolas J, Couvreur P (2013) Stimuli-responsive nanocarriers for drug delivery. Nat Mater 12(11):991-1003

Murthy N, Campbell J, Fausto N, Hoffman AS, Stayton PS (2003) Bioinspired $\mathrm{pH}$-responsive polymers for the intracellular delivery of biomolecular drugs. Bioconjug Chem 14(2):412-419

Nahire R, Paul S, Scott MD, Singh RK, Muhonen WW, Shabb J, Gange KN, Srivastava D, Sarkar K, Mallik S (2012) Ultrasound enhanced matrix metalloproteinase- 9 triggered release of contents from echogenic liposomes. Mol Pharm 9(9):2554-2564

Nogueira E, Gomes AC, Preto A, Cavaco-Paulo A (2016) Folatetargeted nanoparticles for rheumatoid arthritis therapy. Nanomed Nanotechnol Biol Med 12(4):1113-1126

Oliveira IM, Gonçalves C, Reis RL, Oliveira JM (2018) Engineering nanoparticles for targeting rheumatoid arthritis: past, present, and future trends. Nano Res 11(9):4489-4506

Patra JK, Das G, Fraceto LF, Campos EVR, del Pilar R-T, AcostaTorres LS, Diaz-Torres LA, Grillo R, Swamy MK, Sharma S (2018) Nano based drug delivery systems: recent developments and future prospects. J Nanobiotechnol 16(1):71

Peper SM, Lew R, Mikuls T, Brophy M, Rybin D, Wu H, O'Dell J (2017) Rheumatoid arthritis treatment after methotrexate: the durability of triple therapy versus etanercept. Arthritis Care Res 69(10):1467-1472

Pham CT (2011) Nanotherapeutic approaches for the treatment of rheumatoid arthritis. Wiley Interdiscip Rev Nanomed Nanobiotechnol 3(6):607-619

Polyak B, Friedman G (2009) Magnetic targeting for site-specific drug delivery: applications and clinical potential. Expert Opin Drug Deliv 6(1):53-70

Quan L-d, Thiele GM, Tian J, Wang D (2008) The development of novel therapies for rheumatoid arthritis. Expert Opin Ther Pat 18(7):723-738

Rajamäki K, Nordström T, Nurmi K, Åkerman KE, Kovanen PT, Öörni K, Eklund KK (2013) Extracellular acidosis is a novel danger signal alerting innate immunity via the NLRP3 inflammasome. J Biol Chem 288(19):13410-13419

Raza A, Rasheed T, Nabeel F, Hayat U, Bilal M, Iqbal H (2019) Endogenous and exogenous stimuli-responsive drug delivery systems for programmed site-specific release. Molecules 24(6):1117

Roiniotis J, Dinh H, Masendycz P, Turner A, Elsegood CL, Scholz GM, Hamilton JA (2009) Hypoxia prolongs monocyte/macrophage survival and enhanced glycolysis is associated with their maturation under aerobic conditions. J Immunol 182(12):7974-7981 
Sagnella SM, Duong H, MacMillan A, Boyer C, Whan R, McCarroll JA, Davis TP, Kavallaris M (2014) Dextran-based doxorubicin nanocarriers with improved tumor penetration. Biomacromol 15(1):262-275

Sethuraman VA, Na K, Bae YH (2006) pH-responsive sulfonamide/ PEI system for tumor specific gene delivery: an in vitro study. Biomacromol 7(1):64-70

Shen R, Mu B, Du P, Liu P (2011) Preparation of photo-sensitive degradable polymeric nanocapsules from dendrimer grafted nano-silica templates. Soft Mater 9(4):382-392

Shenoy D, Little S, Langer R, Amiji M (2005) Poly (ethylene oxide)modified poly ( $\beta$-amino ester) nanoparticles as a $\mathrm{pH}$-sensitive system for tumor-targeted delivery of hydrophobic drugs 1 In vitro evaluations. Mol Pharm 2(5):357-366

Siafaka PI, Üstündağ Okur N, Karavas E, Bikiaris DN (2016) Surface modified multifunctional and stimuli responsive nanoparticles for drug targeting: current status and uses. Int J Mol Sci 17(9):1440

Singh A, Amiji MM (2018) Stimuli-responsive drug delivery systems. Royal Society of Chemistry, London

Singh P, Pandit S, Mokkapati V, Garg A, Ravikumar V, Mijakovic I (2018) Gold nanoparticles in diagnostics and therapeutics for human cancer. Int J Mol Sci 19(7):100-100

Smolen IS, Aletaha D, Redlich K (2012) The pathogenesis of rheumatoid arthritis: new insights from old clinical data? Nat Rev Rheumatol 8(4):235

Smolen JS, Aletaha D, Barton A, Burmester GR, Emery P, Firestein GS, Kavanaugh A, McInnes IB, Solomon DH, Strand V, Yamamoto K (2018) Rheumatoid arthritis. Nat Rev Dis Primers 4(1):18001

Song N, Liu W, Tu Q, Liu R, Zhang Y, Wang J (2011) Preparation and in vitro properties of redox-responsive polymeric nanoparticles for paclitaxel delivery. Colloids Surf B 87(2):454-463

Song R, Murphy M, Li C, Ting K, Soo C, Zheng Z (2018) Current development of biodegradable polymeric materials for biomedical applications. Drug Des Dev Ther 12:3117

Sostres C, Gargallo CJ, Arroyo MT, Lanas A (2010) Adverse effects of non-steroidal anti-inflammatory drugs (NSAIDs, aspirin and coxibs) on upper gastrointestinal tract. Best Pract Res Clin Gastroenterol 24(2):121-132

Stuart MAC, Huck WT, Genzer J, Müller M, Ober C, Stamm M, Sukhorukov GB, Szleifer I, Tsukruk VV, Urban M (2010) Emerging applications of stimuli-responsive polymer materials. Nat Mater 9(2):101-113

Ta T, Convertine AJ, Reyes CR, Stayton PS, Porter TM (2010) Thermosensitive liposomes modified with poly (N-isopropylacrylamide-co-propylacrylic acid) copolymers for triggered release of doxorubicin. Biomacromol 11(8):1915-1920

Uslu A, Güvenaltın Ş (2010) The investigation of structural and thermosensitive properties of new phosphazene derivatives bearing glycol and amino acid. Dalton Trans 39(44):10685-10691

van der Meel R, Sulheim E, Shi Y, Kiessling F, Mulder WJ, Lammers $\mathrm{T}$ (2019) Smart cancer nanomedicine. Nat Nanotechnol 14(11):1007-1017

Vandewalle J, Luypaert A, De Bosscher K, Libert C (2018) Therapeutic mechanisms of glucocorticoids. Trends Endocrinol Metab 29(1):42-54
Vats M, Mishra SK, Baghini MS, Chauhan DS, Srivastava R, De A (2017) Near infrared fluorescence imaging in nanotherapeutics and photo-thermal evaluation. Int J Mol Sci 18(5):924

Wang S, Lv J, Meng S, Tang J, Nie L (2020) Recent advances in nanotheranostics for treat-to-target of rheumatoid arthritis. Adv Healthc Mater 9(6):1901541

Wen J, Anderson SM, Du J, Yan M, Wang J, Shen M, Lu Y, Segura T (2011) Controlled protein delivery based on enzymeresponsive nanocapsules. Adv Mater 23(39):4549-4553

Wilson DS, Dalmasso G, Wang L, Sitaraman SV, Merlin D, Murthy N (2010) Orally delivered thioketal nanoparticles loaded with TNF- $\alpha$-siRNA target inflammation and inhibit gene expression in the intestines. Nat Mater 9(11):923-928

Xu Y, Mu J, Xu Z, Zhong H, Chen Z, Ni Q, Liang X-J, Guo S (2020) Modular acid-activatable acetone-based ketal-linked nanomedicine by dexamethasone prodrugs for enhanced antirheumatoid arthritis with low side effects. Nano Lett 20(4):2558-2568

Yang B, Jia H, Wang X, Chen S, Zhang X, Zhuo R, Feng J (2014) Selfassembled vehicle construction via boronic acid coupling and host-guest interaction for serum-tolerant DNA transport and pH-responsive drug delivery. Adv Healthc Mater 3(4):596-608

Yoon S, Kim WJ, Yoo HS (2013) Dual-responsive breakdown of nanostructures with high doxorubicin payload for apoptotic anticancer therapy. Small 9(2):284-293

Yu C, Li X, Hou Y, Meng X, Wang D, Liu J, Sun F, Li Y (2019) Hyaluronic acid coated acid-sensitive nanoparticles for targeted therapy of adjuvant-induced arthritis in rats. Molecules 24(1):146

Zhang G, Jiang X (2019) Temperature responsive nanoparticles based on PEGylated polyaspartamide derivatives for drug delivery. Polymers 11(2):316

Zhang T, Sturgis TF, Youan B-BC (2011) pH-responsive nanoparticles releasing tenofovir intended for the prevention of HIV transmission. Eur J Pharm Biopharm 79(3):526-536

Zhang S, Wu L, Cao J, Wang K, Ge Y, Ma W, Qi X, Shen S (2018) Effect of magnetic nanoparticles size on rheumatoid arthritis targeting and photothermal therapy. Colloids Surf B 170:224-232

Zhao J et al. (2017) Multifunctional folate receptor-targeting and $\mathrm{pH}$-responsive nanocarriers loaded with methotrexate for treatment of rheumatoid arthritis. Int J Nanomed 12:6735

Zhao M, Biswas A, Hu B, Joo KI, Wang P, Gu Z, Tang Y (2011) Redox-responsive nanocapsules for intracellular protein delivery. Biomaterials 32(22):5223-5230

Zhao J, Zhang X, Sun X, Zhao M, Yu C, Lee RJ, Sun F, Zhou Y, Li Y, Teng L (2018) Dual-functional lipid polymeric hybrid pHresponsive nanoparticles decorated with cell penetrating peptide and folate for therapy against rheumatoid arthritis. Eur J Pharm Biopharm 130:39-47

Zubris KA, Liu R, Colby A, Schulz MD, Colson YL, Grinstaff MW (2013) In vitro activity of paclitaxel-loaded polymeric expansile nanoparticles in breast cancer cells. Biomacromol 14(6):2074-2082 